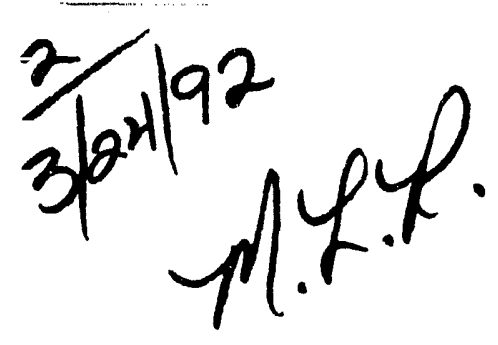

\title{
Treatment and Recycling of Shredder Fluff: Final Report on Phase I, Proof of Concept
}

Energy Systems Division Argonne National Laboratory

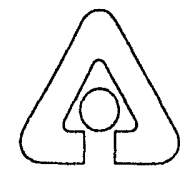

Operated by The University of Chicago, under Contract W-31-109-Eng-38, for the United States Department of Energy 


\section{Argonne National Laboratory}

Argonne National Laboratory, with facilities in the states of Illinois and Idaho, is owned by the United States government, and operated by the University of Chicago under the provisions of a contract with the Department of Energy.

This technical report is a product of Argonne's Energy Systems Division.

For information on the division's scientific and engineering activities, contact:

Director, Energy Systems Division

Argonne National Laboratory

Argonne, Illinois 60439-4815

Telephone (708) 252-3724

\section{Disclaimer}

This report was prepared as an account of work sponsored by an agency of the United States Govemment. Neither thie United States Govemment nor any agency thereof, nor any of their employees, makes any warranty, express or implied, or assumes any legal liability or responsibility for the accuracy, completeness, or usefulness of any information, apparatus, product, or process disclosed, or represents that its use would not infringe privately owned rights. Reference herein to any specific commercial product, process, or service by trade name, trademark, manufacturer, or otherwise, does not necessarily constitute or imply its endorsement, recommendation, or favoring by the United States Govemment or any agency thereof. The views and opinions of authors expressed herein do not necessarily state or reflect those of the United States Govemment or any agency thereof. 
ANL/ESD--13

DE92 009564

ANLESD-13

\section{Treatment and Recycling of Shredder Fluff: Final Report on Phase I, Proof of Concept}

by B.J. Jody, E.J. Daniels, and P.V. Bonsignore

Energy Systems Division,

Argonne National Laboratory, 9700 South Cass Avenue, Argonne, Illinois 60439

February 1992

Work sponsored by United States Department of Energy,

Assistant Secretary for Conservation and Renewable Energy 


\section{Contents}

Acknowledgments...........................................................

Abstract....................................................................... 1

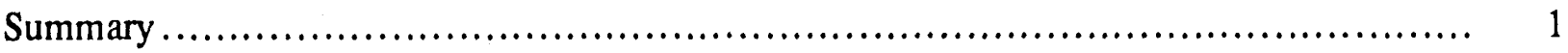

1 Introduction ................................................................ 3

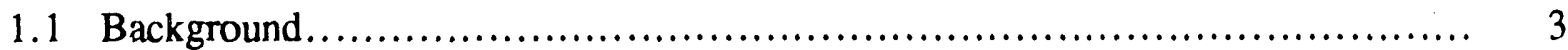

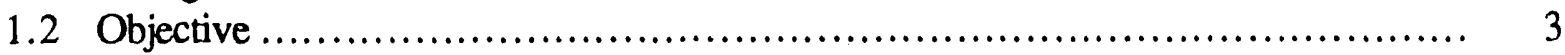

1.3 Characteristics of Shredder Fluff ........................................ 4

2 Alternatives for the Treatment of Shredder Fluff ............................... 6

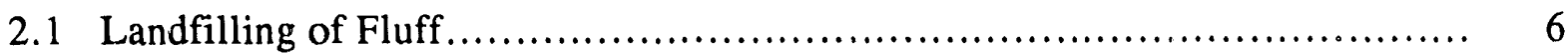

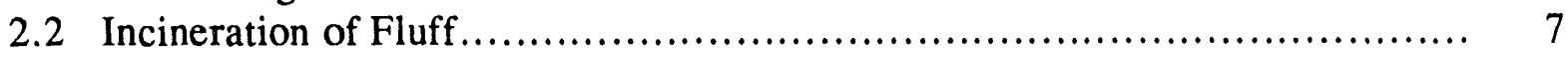

2.3 Incineration of Fluff with Heat Recovery $\ldots \ldots \ldots \ldots \ldots \ldots \ldots \ldots \ldots \ldots \ldots \ldots \ldots \ldots$

2.4 Pelletization and Sale of Fluff as Fuel Supplements........................ 8

2.5 Secondary Recycling of Shredder Fluff..................................... 9

2.6 Chemical Conversion of Fluff to Fuels and Chemicals ...................... 9

3 Basic Process Concept.................................................. 11

3.1 Exploratory Experiments ................................................ 11

3.2 Experiments and Experimental Conditions .................................. 12

3.3 Experimental Apparatus and Procedure .................................... 13

3.3.1 Physical Separation Unit............................................... 13

3.3.2 Solvent Extraction Unit ................................................ 13

3.3.3 Solvent Regeneration Unit............................................ 15

3.4 Results.............................................................. 16

3.4.1 Physical Separation of Shredder Fluff................................. 16

3.4.2 Extraction and Recovery of Plastics ................................ 18

3.4 .3 Solvent Recovery................................................. 21

4 Discussion and Conclusions .............................................. 23

4.1 Revised Concept for the Shredder-Fluff-Treatment Process................. 23

4.2 Preliminary Process Economics ........................................... 25

4.3 Options for Recycling Automotive Plastics ................................ 26

4.4 Conclusions.......................................................... 26

Appendix: Automobile Shredder Residue: Treatment Options ....................... 29 


\section{Figures}

1 Laboratory Apparatus for the Physical Separation of PUF, Fines, and Plastics-Rich Fractions of Shredder Fluff

2 Soxhlet Solvent-Extraction Apparatus ...................................... 15

3 Laboratory Solvent-Recovery Apparatus..................................... 16

4 PUF Recovered from Shredder Fluff ..................................... 17

5 Recovered PUF after Cleaning............................................ 17

6 Recovered PVC/ABS ............................................................. 18

7 Polypropylene and Polyethylene Recovered from Fluff........................... 19

8 Infrared Spectra of Recovered PVC Compared with Analytical-Grade PVC.......... 19

9 Infrared Spectra of Recovered ABS Compared with Analytical-Grade ABS......... 20

10 Partially Cleaned Polypropylene and Polyethylene Recovered from Fluff .......... 20

11 Cleaned and Filtered Polypropylene and Polyethylene Recovered from Fluff ...... 21

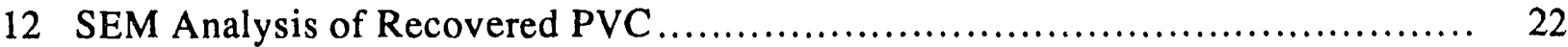

13 Process Concept for Selective Recovery of Shredder Fluff Materials.............. 24

14 Relative Value of Shredder Fluff Compared with Expected Unit Capital Cost for Alternative Recycling Modes.

\section{Table}

1 Solubility of Selected Plastics in Organic Solvents 


\section{Acknowledgments}

We are very grateful to Erika Shoemaker of Argonne National Laboratory (ANL) for conducting the experiments reported in this document. We also acknowledge the guidance provided by the U.S. Department of Energy program manager, Stuart Natof. Our thanks are also extended to the members of the Institute of Scrap Recycling Industries (ISRI) who provided us with the fluff material used in our experiments and to the many who participated in our project reviews, presentations, and discussions. Finally, we would like to express our gratitude to Kevin Brown, ANL, for technical editing; Laurie Culbert, ANL, for graphics; and Leslie Crosser, ANL, for word processing. 


\title{
Treatment and Recycling of Shredder Fluff: Final Report on Phase I, Proof of Concept
}

by

\author{
B.J. Jody, E.J. Daniels, and P.V. Bonsignore
}

\begin{abstract}
This report describes the results of a study conducted by Argonne National Laboratory (ANL) to investigate the feasibility of extracting thermoplastics from shredder fluff for possible recycling. The objective of the research was to evaluate the technical feasibility of using organic solvents to selectively dissolve and recover thermoplastics from the shredder fluff. The basis of the process is physical separation of shredder fluff, which is followed by selective dissolution and recovery of thermoplastics from the plastics-rich stream. In smiall-scale laboratory runs, four potentially marketable products were recovered by the use of this process: clean polyurethane foam (PUF), a mixture of polypropylene (PP) and polyethylene (PE), a mixture of polyvinyl chloride (PVC) and acrylonitrilebutadiene-styrene (ABS), and an iron-rich fine magnetic fraction. Because the residual shredder fluff has been preprocessed, it should be more homogeneous and have a much lower chlorine concentration and moisture content than the raw shredder fluff. These attributes should make the material more economically and environmentally attractive than raw shredder fluff as a fuel or feedstock for the production of fuels and chemicals. A preliminary capital cost estimate of the process was also developed.
\end{abstract}

\section{Summary}

Alternatives to landfilling for the treatment, disposal, and recycling of shredder fluff have been the focus of previous research. These alternatives include the following: (1) incineration for mass and volume reduction, (2) incineration with heat recovery for the production of steam and/or electricity, (3) thermochemical processing (such as gasification and pyrolysis) for the production of fuels and chemicals, and (4) production of secondary materials (such as wood substitutes and polymer concretes). Although most of these alternatives appear to be technically feasible, none are, at this time, sufficiently cost-effective for commercial implementation. In general, the alternatives that have been investigated for the treatment and recycling of shredder fluff parallel those that have been considered for the treatment and recycling of many other types of solid industrial wastes with potential fuel value; the latter alternatives have also had little commercial success. (A prime example is used tires; they are a type of solid waste that is cost-prohibitive for treatment and recycling.) 
Because shredder fluff contains an appreciable, identifiable portion of plastic, Argonne National Laboratory (ANL), with funding provided by the U.S. Department of Energy (DOE), initiated a research program to investigate the feasibility of extracting plastics from shredder fluff for recycling. The concept is attractive for three reasons:

1. Although the postconsumer plastics-recycling market is in its infancy, the market is growing;

2. The plastics content of shredder fluff is expected to increase because of the increasing use of plastics in automobiles, which are the main feedstock to the shredder industry; and

3. Any option for recycling shredder fluff (other than the extraction of plastics as plastics) implies a loss in the value-added potential of the plastics that were originally produced from fuels and chemicals.

The initial objective of the research was to evaluate the technical feasibility of dissolving and recovering thermoplastics from shredder fluff to facilitate the recycling of the recovered plastics. The basis of the process is physical separation of shredder fluff, which is followed by the dissolution and recovery of thermoplastics from the plastics-rich stream. In limited small-scale laboratory runs, four potentially marketable products were identified and recovered by the use of this process: clean polyurethane foam (PUF), a mixture of polypropylene (PP) and polyethylene (PE), a mixture of polyvinyl chloride (PVC) and acrylonitrile-butadiene-styrene (ABS), and an iron-rich fine magnetic fraction.

The recovered PUF, PP, PE, PVC, and ABS from typical shredder fluff could have a market value of up to $\$ 63 /$ ton of shredder fluff processed. A preliminary capital cost estimate, extrapolated from the costs of a similar system that uses solvents for coal processing, indicates that a facility processing $12 \times 10^{3}$ tons/yr of shredder fluff would cost about $\$ 750,000$. At that cost, a simple payback would be expected in about one year, depending on the actual market value of the recovered plastics and the yield of plastics per ton of shredder fluff processed. The amount of plastics recovered is expected to be about $10 \%$ of the initial mass of a "typical" shredder fluff. Nonetheless, the residual shredder fluff would still have a fuel value of about $4.6 \times 10^{3} \mathrm{Btu} / \mathrm{lb}$, and this material could, if it were cost-effective, be used in any of the other proposed recycling schemes for shredder fluff. Because the residual shredder fluff has been preprocessed, it should be more homogeneous and have a much lower chlorine content and moisture concentration than the raw shredder fluff. These attributes should make the material more economically and environmentally attractive than raw shredder fluff as a fuel or feedstock for the production of fuels and chemicals.

The results of experiments conducted to date have indicated that the recovery of the PUF and thermoplastics content of shredder fluff is technically feasible. Although the results are encouraging, the following issues need to be resolved: (1) the market potential of the recovered products, (2) the variability of process outputs from different shredder fluff sources, (3) the relative concentrations of hazardous materials in the different process streams, and (4) the cost- 
effectiveness of the process. Experiments that will address these issues will be carried out over the next year.

With regard to the market potential of the recovered plastics, the work conducted to date has attracted the interest of some of the larger chemical companies that produce automotive plastics. Papers describing the concept and our work have been provided to these companies for technical review.

\section{Introduction}

\subsection{Background}

Each year, the secondary metals industry recovers about 55-60 $\times 10^{6}$ tons of prompt and obsolete scrap that is used in the production of finished steel products. The single largest source of this scrap is the obsolete automobile. The shredder industry recovers about 10-12 $\times 10^{6}$ tons/yr of ferrous scrap, most of which is from shredded automobiles. However, for each ton of steel recovered, about $500 \mathrm{lb}$ of fluff is produced. Shredder fluff consists of the nonmetallic content of the automobile and other materials (and their constituents), such as air conditioners, refrigerators, dryers, and dishwashers - the latter products are commonly called white goods. At present, shredder fluff is disposed of in landfills; however, the rapidly escalating cost of landfilling, as well as concerns about the fate of this waste in the environment, poses a significant liability to the industry.

To address this problem, researchers have focused on exploiting the plastics content of shredder fluff (and other hydrocarbons present in fluff) for secondary recycling (e.g., production of substitutes for wood products) and for quaternary recycling (e.g., energy cogeneration). Limited work has also been conducted on tertiary recycling (e.g., pyrolysis and gasification). Although previous research has established the technical feasibility of most, if not all, of the alternatives that were examined, none of the alternatives have proven to be cost-effective.

This report discusses the results of the first phase of research done at Argonne National Laboratory (ANL) to test and develop an unexplored concept involving the dissolution, extraction, and recovery of plastics from shredder fluff to make the recycling of plastics easier.

\subsection{Objective}

The objective of this research and development program is to develop a cost-effective alternative to landfilling shredder fluff. The increasing cost of disposing of shredder fluff in landfills limits (and perhaps threatens) the economic viability of processing obsolete automobiles for the recovery of recyclable metals. The initial focus of this effort was to determine the technical feasibility of a process that could selectively recover the thermoplastics constituents of shredder

fluff for recycling. Such a process is appealing for the following reasons: (1) the market for recycled plastics is growing, (2) the use of automotive plastics is expected to increase, and (3) the 
use of any other recycling option may result in the loss of the potential value of the plastics content of the shredder fluff.

\subsection{Characteristics of Shredder Fluff}

Shredder fluff is a very heterogeneous waste material; not only does its composition vary from site to site, but it changes daily even at the same site. Shredder fluff contains plastics (thermoplastics, thermosets, and polyurethane foam [PUF]), rubber, wood, paper, fabrics, glass, sand, dirt, ferrous and nonferrous metal pieces, tar, and any other materials that may remain in a vehicle when it is scrapped. Overall, shredder fluff consists of about $50 \%$ combustible material and $50 \%$ noncombustible (inert) material. The plastics content of shredder fluff is typically about $15-20 \%$ by weight. This proportion is expected to increase over the next decade because the use of automotive plastics has increased significantly over the past 10-15 yr. The shredder fluff may also contain brake fluid, gasoline, engine oil, windshield washing fluids, antifreeze (ethylene glycol), Freon $^{\mathrm{TM}}$ refrigerants, and in some cases polychlorinated biphenyls (PCBs). (PCB contamination can result from the shredding of old white goods that may have intact capacitors.) In addition, shredder fluff may contain heavy metals, such as lead, mercury, and cadmium. Shredder fluff also contains varying amounts of moisture, depending on the type of shredding operation (i.e., wet or dry) and if it is exposed to rain while in inventory. An approximate composition of shredder fluff is as follows:

$\begin{array}{lr}\text { Plastics } & 15-20 \% \\ \text { Paper, wood, and tar } & 15-25 \% \\ \text { Inert material } & 25-75 \% \\ \text { Moisture } & 2-35 \%\end{array}$

The composition of the plastics portion of a 1981 model U.S. passenger car was reported to include the following:*

$\begin{array}{lr}\text { Polyurethane foam } & 23 \% \\ \text { Reinforced plastics (RP), } & \\ \quad \text { bulk molding compound (BMC), } & \\ \quad \text { and sheet molding compound (SMC) } & 22 \% \\ \text { Polypropylene (PP) } & 19 \% \\ \text { Polyvinyl chloride (PVC) } & 15 \% \\ \text { Acrylonitrile butadiene styrene (ABS) } & 7 \% \\ \text { Nylons } & 4 \% \\ \text { Other } & 10 \%\end{array}$

Thermoplastics (such as PP, ABS, and PVC) appear to account for a significant share of the plastics anticipated to be contained in shredder fluff. Because thermoplastics are amenable to recycling as plastics, these materials are the focus of the separation technology under investigation by ANL.

\footnotetext{
"see article by McClellan, T.R., 1983, in Modern Plastics, pp. 50-52, Feb.
} 
Also, the density and shape of shredder fluff is heterogeneous. For example, the PUF, with absorbed moisture and oils, might represent about $10 \%$ of the shredder fluff mass but could represent over $50 \%$ of its volume. On the other hand, fines $(<1 / 4$ in.) might represent about $25 \%$ of the mass and only about $5 \%$ of the volume. The volume ratios of the large and small PUF pieces could be as high as $250: 1$. The physical variability of shredder fluff is problematic for recyclers and is obviously of significant importance in the development of efficient reclamation technology. 


\section{Alternatives for the Treatment of Shredder Fluff}

Research reported in the literature indicates that all of the four generic modes of recycling (primary, secondary, tertiary, and quaternary) can be applied to shredder fluff because of its plastic and hydrocarbon content and its inherent fuel and chemical value. All four modes have been investigated to varying degrees. (A document summarizing the literature and providing the relevant references is an appendix to this report.) Most of the reported research has focused on exploiting the plastics and other hydrocarbons in the shredder fluff for secondary recycling (e.g., production of substitutes for wood products) and for quaternary recycling (e.g., energy cogeneration). Limited work has also been reported on tertiary recycling (e.g., pyrolysis, gasification, and PUF hydrolysis). The only reference to the potential of primary recycling (i.e., recovery of "pure" plastics) was the early work conducted by the U.S. Bureau of Mines to physically separate various plastics from shredder fluff.*

Although many alternatives for recycling shredder fluff have been reported in the literature, there is little mention of preprocessing the shredder fluff in order to concentrate the constituents of shredder fluff for which the recycling technology is targeted, except for the work conducted by the U.S. Bureau of Mines. We anticipate that, regardless of the type of recycling mode employed, some form of physical separation will be essential to concentrate the target recyclable constituents and reduce the chemical variability and/or the particle size distribution of shredder fluff.

A brief discussion of the alternatives that have been considered for the disposal, treatment, and recycling of shredder fluff follows.

\subsection{Landfilling of Fluff}

Landfilling is the default option for the disposal of shredder fluff. Although the cost of landfilling has escalated dramatically over the past few years, snme shredders can dispose of shredder fluff in conventional landfills at costs of less than $\$ 25 /$ ton, while others pay over $\$ 80 /$ ton. Some shredders must transport their fluff out of state to dispose of it in landfills. If shredder fluff were classified as hazardous, landfill costs would increase by at least a factor of ten (if the shredder fluff were not treated prior to landfilling). Several commercial processes that can "fix" the hazardous materials that may be contained in shredder fluff are available, and such processes can make the fluff safe for disposal in conventional landfills. The cost of these processes varies, depending on the materials present in the shredder fluff and the type of process used. The leastexpensive options appear to be chemical fixation techniques, which are estimated to cost about $\$ 10-20 /$ ton of shredder fluff.

\footnotetext{
*Primary recycling generally refers to the reuse of a recovered material to produce the same product as that originally produced from virgin material. Within the context of shredder fluff, we would consider the recovery of plastics for reuse as plastics, as opposed to as a substitute for lumber, as primary recycling. This definition does not, however, mean that the recovered plastics are necessarily used for the same automotive application as the virgin material. If the recovered plastics are used to displace the need for virgin plastics in any application, we would consider this as "primary" recycling.
} 
Although landfilling is a viable disposal option in many cases, its continued viability is a critical concern. The ongoing "cradle-to-grave" regulatory liability of landfilling compounds that concem.

\subsection{Incineration of Fluff}

Generally, shredder fluff has a fuel value equivalent to that of a low-grade, high-ash coal. EnerGroup reported (see appendix) that the higher heating value of 12 samples of shredder fluff ranged from $2.9 \times 10^{3}$ to $9.26 \times 10^{3} \mathrm{Btu} / \mathrm{bb}$, with an average of $5.4 \times 10^{3} \mathrm{Btu} / \mathrm{lb}$. The moisture content of the samples ranged from 2 to $35 \%$, and the as content of the samples ranged from 25 to $70 \%$. Incineration could reduce the mass of the shredder fluff for disposal by about $50 \%$. However, shredder fluff may contain high concentrations of chlorine and sulfur, and the gases that result from the combustion of these $F^{*}$.nents require scrubbing. Chlorine and sulfur can be scrubbed before combustion by adding materials (such as limestone or dolomite) to the incinerator so that they report to the ash rather than the combustion gas. In either case, because of the variability in the content of acid-gas precursors in the shredder flufi, a significant overdesign of the scrubbing capability will be needed, which vi. ' significantly affect cost. For example, the chlorine content of the 12 samples tested by EnerGreup ranged from 0.7 to $16.9 \%$. The scrubbing technology for this material would have to be designed to accommodate the rnaximum expected concentration of acid-gas precursors. Regardless of whether the acid-gas compounds are scrubbed in the incinerator and report to the ash or whether they are scrubbed from the combustion gas and become a scrubber effluent (either sludge or solid), an excess of solid waste beyond the initial ash content of the shredder fluff will also have to be disposed of. The potential presence of PCBs in the shredder fluff exacerbate the cost and complexity associated with the incineration of raw shredder fluff.

Although incineration is technically feasible, it is also capital-intensive. For example, an incinerator sized to process about $12 \times 10^{3}$ tons/yr of shredder fluff (operating at design capacity for $7,884 \mathrm{~h} / \mathrm{yr}$ ) is estimated to cost over $\$ 1$ million. A simple payback could be achieved in three year's or less only if landfill costs exceeded $\$ 60 /$ ton of shredder fluff (if a mass reduction of about $50 \%$ of the input shredder fluff is assumed and incineration operating costs are ignored).

Off-site incineration of the shredder fluff at a large-scale waste incineration facility, if such a facility were available, would eliminate the need for the capital investment, but off-site incineration would not significantly affect the economics of incineration as an option. Anecdotal evidence suggests that off-site incineration of shredder fluff is a less-desirable alternative than costs alone would indicate. Most incinerator operators are paid for mass reduction of the material processed. Although shredder fluff might have a good heating value in terms of wastes, this attribute does not enter into the equation as significantly as do the high ash content of shredder fluff and the: more than adequate supply of low-ash wastes competing for the limited incineration capacity. 


\subsection{Incineration of Fluff with Heat Recovery}

Incineration with heat recovery for the production of steam or electricity is an alternative to straight incineration for mass or volume reduction. This alternative is also technically feasible; the only technical uncertainty rests with the combustion process, as in the case of incineration. Again, the issue is one of capital costs and economics; nonetheless, there is an opportunity for significantly reducing the payback relative to the investment required, especially in the case of steam (i.e., if there is an on-site use for the steam).

For example, an incinerator with a design capacity of $12 \times 10^{3}$ tons/yr of shredder fluff that is fitted with a heat-recovery steam generator could produce about $14 \times 10^{3} \mathrm{lb} / \mathrm{h}$ of steam (at $10^{3} \mathrm{Btu} / \mathrm{lb}$, a boiler efficiency of $85 \%$, a shredder fluff heating value of $5.4 \times 10^{3} \mathrm{Btu} / \mathrm{lb}$, and $7,884 \mathrm{~h} / \mathrm{yr}$ ). The estimated capital cost of such a system would be about $\$ 1.6$ million. If the steam were valued at about $\$ 5 / 10^{3} \mathrm{lb}$ (the fuel cost component of steam produced in a conventional gas-fired boiler, based on a natural gas price of $\$ 4 / 10^{6} \mathrm{Btu}$ ), the annual value of the steam would be about $\$ 550,000$. If landfill costs were $\$ 60$; ton of shredder fluff, incineration would save approximately $\$ 360,000 / y \mathrm{r}$ in landfill costs, which would yield a simple payback in less than two years. Few shredder facilities, however, have a use for steam.

If the heat were recovered for the production of electricity, the amount of electricity that could be produced (again, on the basis of $12 \times 10^{3}$ tons/yr of shredder fluff) would be about $115 \times 10^{6} \mathrm{kWh} / \mathrm{yr}$ (on the basis of an electricity' generation efficiency of 30\%). The estimated cost of the equipment would be about $\$ 2.4$ million. If the value of the electricity were $\$ 0.08 / \mathrm{kWh}$, its annual value would be $\$ 920,000$, which, when added to a landfill cost savings of $\$ 360,000 / \mathrm{yr}$, would also yield a simple payback in less than two years.

\subsection{Pelletization and Sale of Fluff as Fuel Supplements}

Another proposed option is compacting the fluff to produce pellets that can be sold as a supplemental fuel in coal-fueled or solid-waste-fueled boilers. The estimated cost of pelletizing, briquetting, or cubing shredder fluff by using binders is about $\$ 20 /$ ton. The cost of the binders is estimated at about $\$ 6 /$ ton of shredder fluff. Previous attempts to compact shredder fluff have been unsuccessful primarily because of the high foam and moisture content of the raw shredder fluff. Chemical binders, which have been tested at ANL for producing refuse-derived fuel pellets, might also be applicable for the treatment of shredder fluff.

This option is attractive because it is the least capital-intensive alternative available to the shredder (other than a secondary market for raw shredder fluff). We estimate that to process $12 \times 10^{3}$ tons/yr of shredder fluff, the materials handling equipment and pelletizer would cost about $\$ 250,000$. The potential value of shredder fluff as a supplemental fuel would have an upper limit equivalent to that of coal, at most $\$ 1.50 / 10^{6} \mathrm{Btu}$ or approximately $\$ 16 /$ ton c f shredder fluff. Thus, this alternative would result in a simple payback in slightly more than a year, assuming that the pellets were marketable. 
The market, however, for shredder fluff as a supplemental fuel might be constrained regardless of its quality or price. For example, a single $10^{3}-\mathrm{MW}$ electricity-generating plant consumes about $10^{3}$ tons of coal per day, with an approximate heat content of $2.40 \times 10^{11} \mathrm{Btu}$. A median shredder operation produces $12 \times 10^{3}$ tons/yr of residue (or, on a constant daily basis, about 32 tons/d) with an approximate heat content of $345 \times 10^{6} \mathrm{Btu}$. The average amount of residue available from a single shredder would appear to be so trivial (relative to the coal required for a typical power plant) that the utility should be indifferent and even perhaps be a "good neighbor" and dispose of the shredder residue at no cost to the shredder. Most utilities, however, must obtain permits for the fuels that are used in their power plants. The transactions costs of permitting procedures that are required for the approval of an alternative fuel might preclude the utility from using a fuel supply that meets less than a tenth of a percent of the fuel needs of a single plant. On the other hand, pelletized shredder fluff might be a viable alternative fuel for smallcapacity, solid-fuel-fired industrial or utility boilers.

\subsection{Secondary Recycling of Shredder Fluff}

Because of the relatively high plastics content of raw shredder fluff, its use as a material for the production of secondary products (such as park benches, lamp posts, road traffic furniture, and shingles and other construction materials) has been given some consideration. The key limitations of this approach to recycling shredder fluff (even if such an approach were technically and economically feasible) are that (1) the market for such products is small and (2) the cost of making such secondary products is not insignificant. These limitations make it more difficult for these products to compete with their virgin-material counterparts, such as wood, sand, and gravel, even when one considers that the cost of disposal has been avoided.

\subsection{Chemical Conversion of Fluff to Fuels and Chemicals}

Tertiary recycling of the hydrocarbon-based fraction of shredder fluff (i.e., plastics, rubber, paper, and wood) could produce value-added products (such as monomers, solvents, light hydrocarbons, and liquid and gaseous fuels). Processes that can be employed for this purpose include hydrolysis, gasification, and pyrolysis.

The applicability of hydrolysis, which involves reactions with water generally at elevated temperatures, has been investigated for the treatment of polyurethane foam in shredder fluff. Hydrolysis is also applicable for the treatment of polyesters, polycarbonates, and polyamides. The hydrolysis of PUF produces two main products: polyols and amines. A process to separate and purify the product mix in order to produce polyols was also developed in the mid-1980s (see appendix). The recovered polyols can replace up to $50 \%$ of the virgin polyol (when clean PUF is the input hydrolysis material) that is used in making high-quality, flexible, low-density PUF. Although the chemical conversion of PUF is technically feasible, the market price for clean waste PUF (as a commodity) strongly influences the process economics. For example, clean industrial waste PUF, often used as a raw material for carpet backing, sells for $\$ 0.25-0.40 / \mathrm{lb}$. 
Gasification could also be used to convert the hydrocarbon-based solids in the shredder fluff into a low-Btu synthesis gas. A gasification test run was conducted on shredder fluff mixed with waste oils and automotive plastics by employing the VOEST-ALPINE Industrienlagenbau Ges.m.b.h. high-temperature gasification process (see appendix). An analysis of the clean product gas showed that its heating value was i bout $95 \mathrm{Btu} / \mathrm{ft}^{3}$. (For comparison, natural gas that is considered "pipeline-quality" gas has a heating value of about $10^{3} \mathrm{Btu} / \mathrm{ft}^{3}$.) As a result of gasification, $47.5 \%$ of the energy input of the material gasified was converted to product gas, and the balance was converted to heat. If the shredder fluff were gasified without the addition of waste oil and plastics, the heating value would be even lower. Experience with low-Btu gas derived from other sources (such as coal) has shown that it is uneconomical to transport such a gas to offsite users. Therefore, the product gas would have to be used in close proximity to the gasification facility.

In addition, gasification is extremely capital-intensive. For example, the estimated cost of a $10 \times 10^{3}$-ton/d coal-gasification facility is about $\$ 1.5$ billion. If we ignore the cost benefits associated with the size of a coal-gasification facility, the estimated cost of a facility for gasifying $12 \times 10^{3}$ tons/yr of shredder fluff is about $\$ 4.5$ million. At a $50 \%$ conversion of the fuel value of the shredder fluff to synthesis gas, such a facility would produce about $65 \times 10^{9} \mathrm{Btu} / \mathrm{yr}$ of synthesis gas. If the gas were valued at $\$ 5 / 10^{6} \mathrm{Btu}$ (which is highly unlikely), the revenue potential would be about $\$ 325,000 / \mathrm{yr}$. If the avoided landfilling costs are estimated at $\$ 360,000 / \mathrm{yr}$, the simple payback for gasification is about $6.5 \mathrm{yr}$.

Pyrolysis is the thermal decomposition of organic molecules in an oxygen-deficient atmosphere. Pyrolysis yields a product mix whose composition is generally a function of the operating conditions, primarily temperature. The applicability of pyrolysis for the treatment of plastics is very well known. A catalytic pyrolysis process for the conversion of polyethylene (PE) to liquid fuels has been developed in Japan. The capital cost for a $5 \times 10^{3}$-ton/yr-capacity plant (single-shift operation) has been reported to be $\$ 4$ million. The product output is expected to be $85 \%$ liquid fuels, $15 \%$ gaseous fuel, and $5 \%$ coke. This output would imply that the estimated capital cost for a shredder-fluff-pyrolysis unit with a $12 \times 10^{3}$-ton/yr capacity (three-shift operation) would be about $\$ 3.2$ million. If we assume a $75 \%$ saleable liquid-product yield, such a facility would be expected to produce about $750 \times 10^{3} \mathrm{gal} / \mathrm{yr}$ of liquid fuel (at about $125 \times 10^{3}$ Btu/gal). At a product price of about $\$ 0.75 / \mathrm{gal}$, the annual revenue would be about $\$ 560,000$, which, when added to the savings in landfilling costs of $\$ 360,000 / y r$, would yield a simple payback in a little over three years. (Because Japan has extremely limited landfill space, the alternative to recycling in that country is incineration. Incineration costs in Japan have been reported at about $\$ 300 /$ ton, a value that would imply a simple payback for shredder fluff pyrolysis relative to incineration in less than a year.) In addition to their work on plastics, the Japanese are also reportedly developing technology for chemical conversion (gasification and pyrolysis) of shredder fluff. When faced with a disposal cost of $\$ 300 /$ ton, the Japanese find that even capitalintensive technologies begin to look attractive. 


\section{Basic Process Concept}

Although a number of alternatives for the disposal, treatment, and recycling of shredder fluff are the subject of ongoing research and development, most are not cost-effective, and none focus on the recovery of thermoplastics from shredder fluff for their reuse as thermoplastics. Even the conversion of shredder fluff to fuels and chemicals is a loss in the potential value of plastics, which are derived from fuels and chemicals in the first place. The concept of recovering plastics from shredder fluff for reuse as plastics is appealing for the following reasons: (1) the plastics content of shredder fluff is expected to increase, (2) the market for plastics use in automobiles is growing, and (3) the plastics recycling industry, although still in its infancy, is growing, and we believe that it will continue to grow.

Thermoset plastics (which cannot be reused as plastics except as fillers in composites) are not soluble in organic solvents, although many thermoplastics are (Table 1). On the basis of the expected plastics content of shredder fluff presented in Sec. 1.3, we would expect that more than $60 \%$ of the total thermoplastics content of shredder fluff might be recoverable through the dissolution of the plastic in solvents. Conceptually, because of differences in the solubilities of certain plastics and their differences in susceptibility to specific solvents, the intent of the envisioned basic process concept was to develop a process for extracting specific individual plastics or groups of compatible plastics from shredder fluff using solvents.

\subsection{Exploratory Experiments}

By visually inspecting the shredder fluff, one can see the heterogeneity and complexity that result when it is processed using solvents on an as-received basis. Exploratory tests were performed in which some "as-received" shredder fluff (except for the removal of large pieces that did not fit in the reactor) was added to a 5 -L reactor containing xylene. The reactor and its contents

TABLE 1 Solubility of Selected Plastics in Organic Solvents

\begin{tabular}{ll}
\hline \multicolumn{1}{c}{ Thermoplastic } & \multicolumn{1}{c}{ Solvents } \\
\hline ABS & Chlorinated hydrocarbons (e.g., ethylene dichloride [EDC]) \\
PE & Hot aromatic and chloroaromatic hydrocarbons \\
Polystyrene & Aromatic and chlorinated hydrocarbons \\
PVC & Esters, ketones, chlorinated hydrocarbons \\
Acrylics & Aromatic and chlorinated hydrocarbons, ketones and esters \\
PP & Hot aromatic and chloroaromatic hydrocarbons \\
\hline
\end{tabular}


were heated to the boiling point of the solvent. Although most of the PUF pieces floated, some remained entangled in the shredder fluff. The PUF occupied most of the reactor's volume. Very fine material was also suspended in the solvent, and this material contributed to the solvent's immediate discoloration and cloudiness. On the basis of the results of these preliminary tests, we concluded that separation of the PUF and fines was necessary prior to solvent extraction of its plastics content.

The oils in the shredder fluff also dissolved rapidly, giving the solvent a blackish color. Because the oils are more readily soluble than the plastics, the oils (using a different solvent or different operating conditions from those used to extract the plastics) needed to be removed before the recovery of the plastics was attempted. The moisture content could also be lowered if acetone were used as the oil-extraction solvent because water and acetone are completely miscible.

Exploratory experiments were also conducted using bulk shredder fluff and shredder fluff that had been re-shredded in a wire shredder (to significantly reduce the size of the particles). Although the re-shredded material was easier to handle, at least from an experimental perspective, the dissolution rate did not appear to be significantly faster than that of the bulk shredder fluff. Any improvement in the dissolution rate does not appear to justify the additional cost of reshredding the bulk fluff (estimated at $\$ 20 /$ ton). Subsequent experiments were conducted on asreceived shredder fluff. Large pieces that would not fit in the reactor were excluded (separated by hand) or broken manually into smaller pieces.

\subsection{Experiments and Experimental Conditions}

The following plastics were selected for recovery because they represent the largest share of thermoplastics present in shredder fluff: PP, PE, ABS, and PVC. To recover the targeted plastics, the following solvents were selected for testing in this phase of the program:

1. Acetone and hexane were selected for the removal of the oils, although acetone would probably be preferable because hexane is extremely flammable, forms an azeotrope with water, and does not readily "wet" the materials.

2. Tetrahydrofuran (THF) and EDC were initially selected to dissolve the ABS and the PVC.

3. Xylene was selected to dissolve PP and PE.

The experiments were conducted in a Soxhlet apparatus at the boiling point of the solvents (described in the next section). The operating sequence involves first extracting the altomotive fluids that are present in the shredder fluff, then extracting the PVC and the ABS, and finally extracting the PP and PE. In all of the experiments, excess solvent was used with about a 3:1 mass ratio of solvent to shredder fluff. The solvents were recovered after each experiment. 


\subsection{Experimental Apparatus and Procedure}

\subsubsection{Physical Separation Unit}

Initial attempts to separate the shredder fluff into three fractions (PUF, a plastics-rich stream, and fines) by using a small, commercially available multideck-vibrating-screen (Sweco) unit were not successful. Within a brief period, the wires in the shredder fluff caused "stapling" or plugging of the openings in the upper deck screen. Small pieces of plastic and nonplastic materials were trapped in the fuzz and PUF, and they could not be shaken loose by the vibrating screens. A laboratory classification column was built and fitted with several screens, and it was equipped with a variable-output air blower positioned in the bottom of the apparatus that could be cycled on and off to agitate the shredder fluff as it was separated (Figure 1). This modification largely resolved the stapling problem encountered with the Sweco unit. It also pushed the light PUF to the top of the top screen and liberated some of the PUF's entrained dust and fines content. Because no material left the column during the agitation and separation process (except for some fines that dropped out of the bottom of the column), the unit was operated in a batch mode. An elephant trunk, connected to a vacuum system that can be activated when the blower is in the off mode, was attached to the top of the column. This modification resulted in the separation of the foam from the top of the top screen.

\subsubsection{Solvent Extraction Unit}

The Soxhlet extraction apparatus used in the experiments (see Figure 2) was made up of three basic units: (1) a solvent reservoir, (2) an extraction (or sample) chamber, and (3) a condenser. The solvent reservoir was a 2 - or 5- $\mathrm{L}$ round flask placed in an electrical heating mantel. The temperatures of the solvent and the mantel were monitored and used to control the heating circuits. The difference between the two temperatures at steady state was limited to $10^{\circ} \mathrm{C}$ in order to provide uniform heating and prevent localized overheating in the solvent. The sample chamber that contained the shredder fluff was in the center of the apparatus. During the extraction process, the vaporizing solvent passed through the annulus between the two chambers; therefore, the sample chamber was maintained at the boiling point of the solvent. After the solvent vapor passed through the annulus, it entered the water-cooled condenser, within which it condensed and dropped into the sample chamber.

The operating sequence may be summarized by the following steps:

1. The solvent was loaded in the solvent reservoir, and then the shredder fluff sample was loaded into the sample chamber.

2. The condenser was mounted onto the system, and a flow of cooling water was started.

3. The temperature controller was set at the proper settings, and the solvent was heated. 


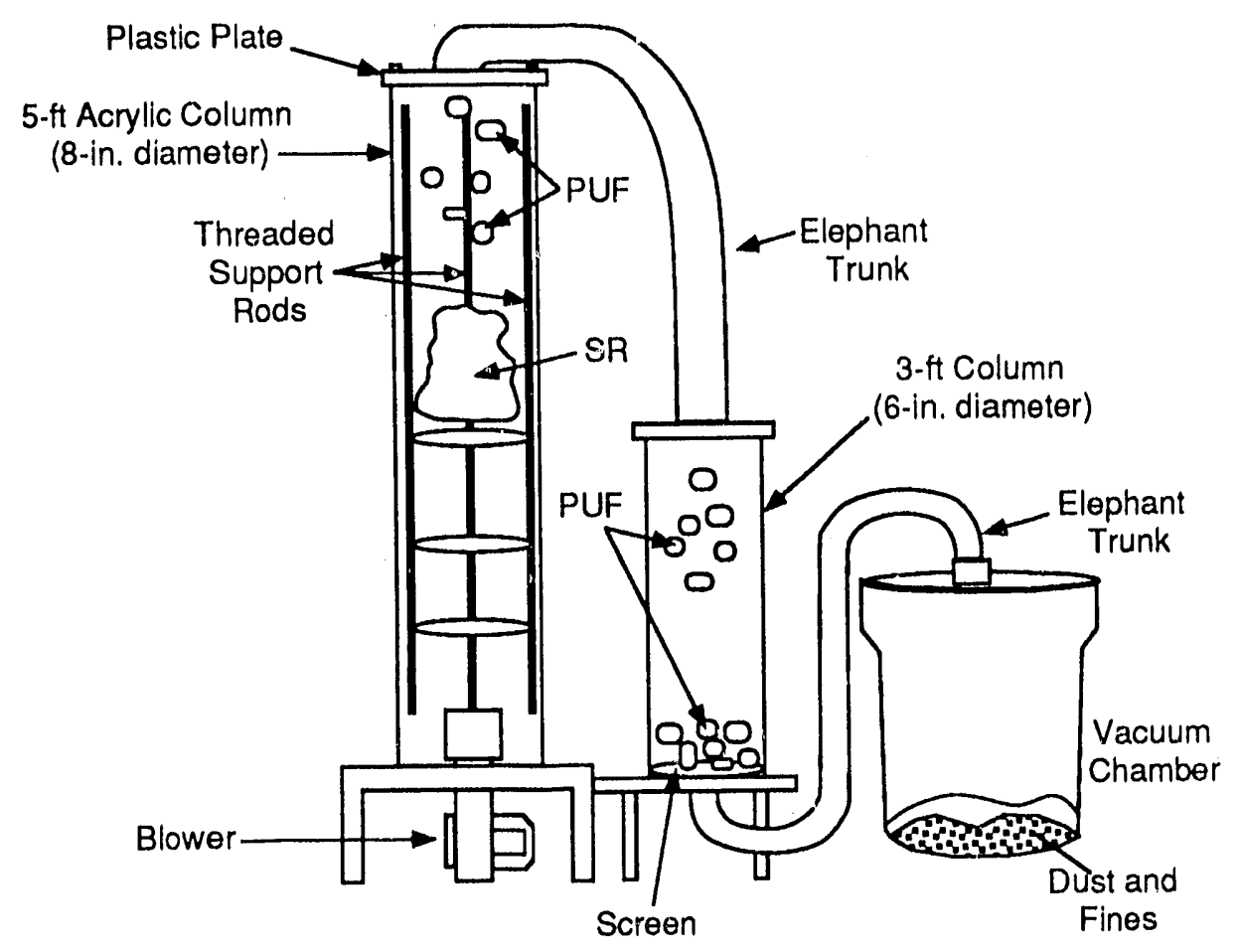

FIGURE 1 Laboratory Apparatus for the Physical Separation of PUF, Fines, and Plastics-Rich Fractions of Shredder

4. As the solvent began to boil, the vapor rose through the annulus and into the condenser, within which it condensed and fell back into the sample chamber to soak the shredder fluff.

5. As the solvent building up in the sample chamber reached a certain level (as determined by an inverted- $U$ tube connecting the sample chamber and the solvent reservoir), the solvent was discharged out of the sample chamber and into the solvent reservoir.

6. The filling and emptying of the sample chamber with solvent continued until the discharged solvent was no longer carrying any dissolved material. This determination was made on the basis of (1) the color of the discharged solvent and (2) an analysis of a sample of the discharged liquid. (A few milliliters of the solvent would be removed and evaporated in order to check for a solid residue. When no solid residue was detected, the extraction process was considered completed.)

7. The apparatus was dismantled when no solids were detected. After the apparatus and all its contents had cooled to room temperature, the shredder fluff sample was emptied into a vessel of known mass and weighed. 


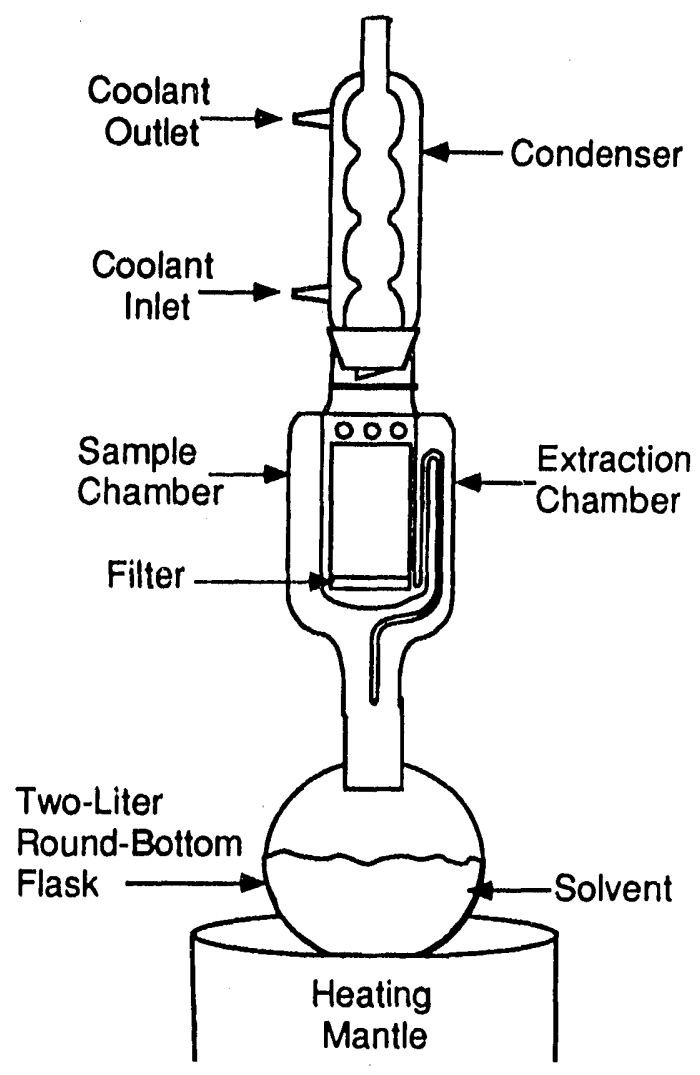

FIGURE 2 Soxhlet Solvent-Extraction

Apparatus

8. The vessel was then connected to a water-cooled condenser and heated to dry the shredder-fluff sample and recover solvent retained in the shredder fluff.

9. The vessel containing the recovered solvent was then disconnected and weighed again. (The apparatus was basically the same as that discussed below for solvent recovery.)

10. The dried sample was spread in a clean tray and allowed to dry overnight in the hood, and it was weighed again.

\subsubsection{Solvent Regeneration Unit}

The solvent reservoir that contained the dissolved plastics was then connected to the solvent-recovery system, as shown in Figure 3. The solvent was boiled off and condensed, and the residual solids (mostly plastics) were collected from the reservoir. Because plastics stick to glass after the solvent evaporates, the solvent-recovery system was not run to completion so as to not ruin the glass reactor and jeopardize the mass-balance calculations. Instead, after most of the 


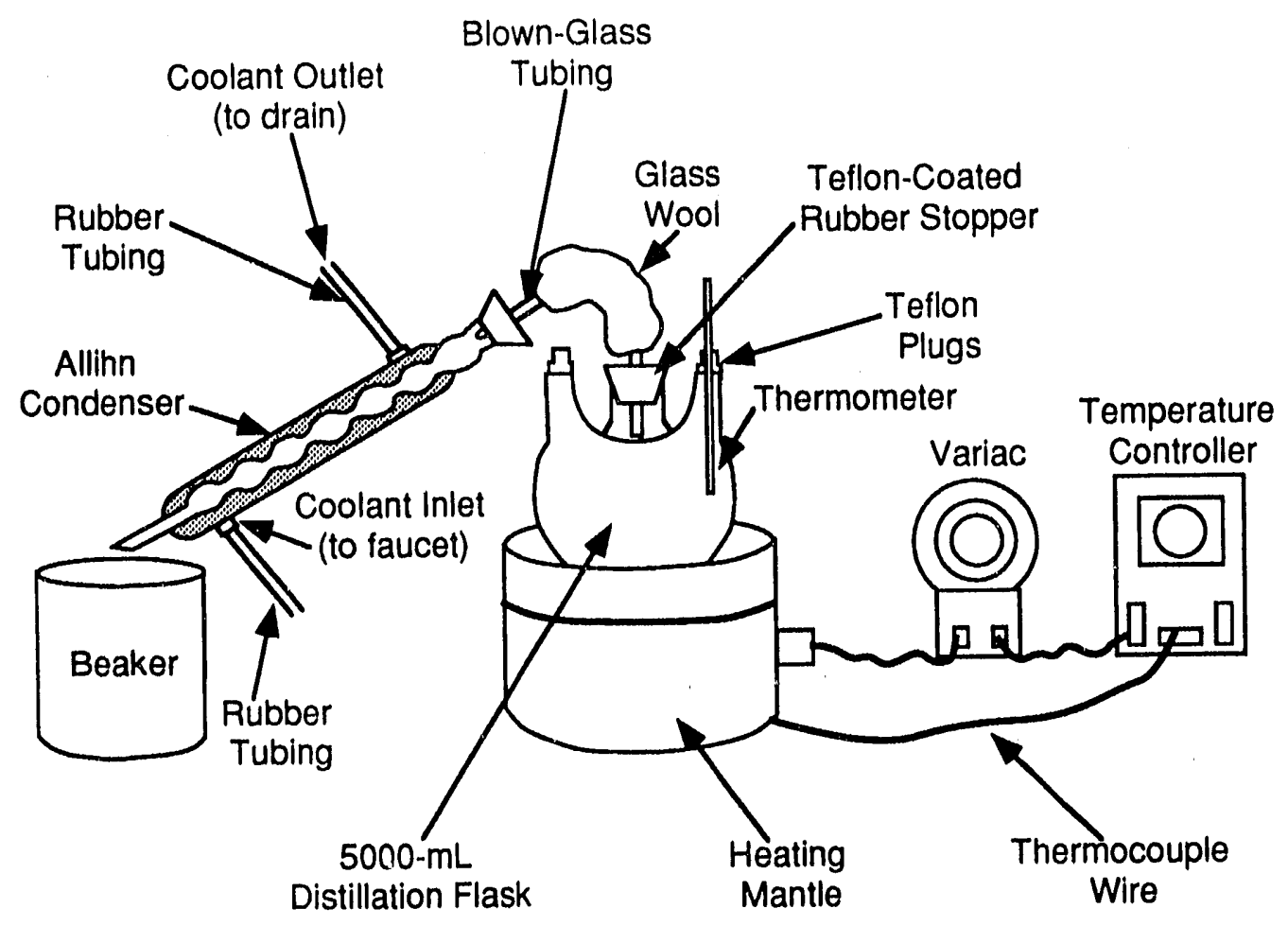

FIGURE 3 Laboratory Solvent-Recovery Apparatus

solvent had been boiled-off and recovered, the thickened plastic pregnant solution was poured into a clean tray, weighed, and allowed to dry overnight in the hood.

\subsection{Results}

Because large variations in the composition of shredder fluff can exist within the same pile of shredder fluff, generalizations about the quantitative data presented here should be made cautiously. We believe that the data are qualitatively very sound. One should expect quantitative variations, however, because of the variability in the composition of shredder fluff.

\subsubsection{Physical Separation of Shredder Fluff}

Several sizes of screens, ranging from $1 / 16$ in. to $1.5 \mathrm{in}$., were used to separate as-received shredder fluff. With this procedure, the shredder fluff was separated into three fractions (PUF, a plastics-rich stream, and fines) by using only one 1/4-in. screen with the screen's overhead space connected to a vacuum chamber.

The PUF fraction, which absorbed oils and moisture, represented about $10 \%$ of the shredder fluff mass and over $30 \%$ of its volume. (On average, because large PUF pieces were removed manually before the shredder fluff was shipped to our laboratory, shredder fluff is expected to contain more PUF than that recovered in these experiments.) The recovered PUF was 
treated first with a mild solvent (either acetone or hexane) to extract and recover the oils and then washed with a water/detergent solutic $a$ to remove the dirt. This treatment reduced the weight of the recovered dirty PUF by $35 \%$. Fi $i_{\text {g }}$ ures 4 and 5 show the PUF before and after cleaning. The cleaned PUF contained some fuzz (and in one case, a small piece of wire), lacked any odor and visible dirt, and probably would be adequate as a feed for hydrolysis. The cleaned PUF might also be acceptable as a raw material for carpet backing.

The fines fraction (<1/4-in. particles) represented about $27 \%$ of the shredder fluff mass. A magnet was used to further separate a fines fraction, which was found to contain $30-40 \%$ magnetic material. The magnetic fraction was analyzed and found to contain $64 \%$ iron, $0.54 \%$ zinc, $0.24 \%$ copper, $0.1 \%$ lead, $0.07 \%$ chromium, $0.27 \%$ aluminum, and the residual was essentially oxygen. The fine magnetic fraction appears to be equivalent in composition to a high-grade ore fine, such as that used to produce iron pellets. The $0.54 \%$ zinc present in the magnetic fines may make it less attractive. The nonmagnetic fraction contained sand, glass, gravel, and some nonmagnetic metallic fines.

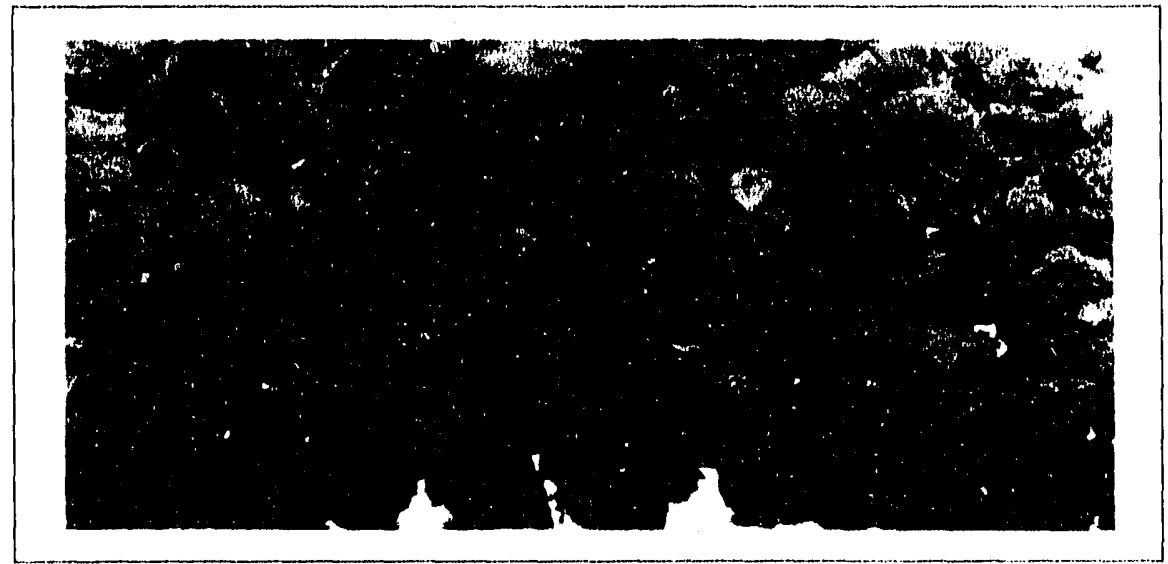

FIGURE 4 PUF Recovered from Shredder Fluff

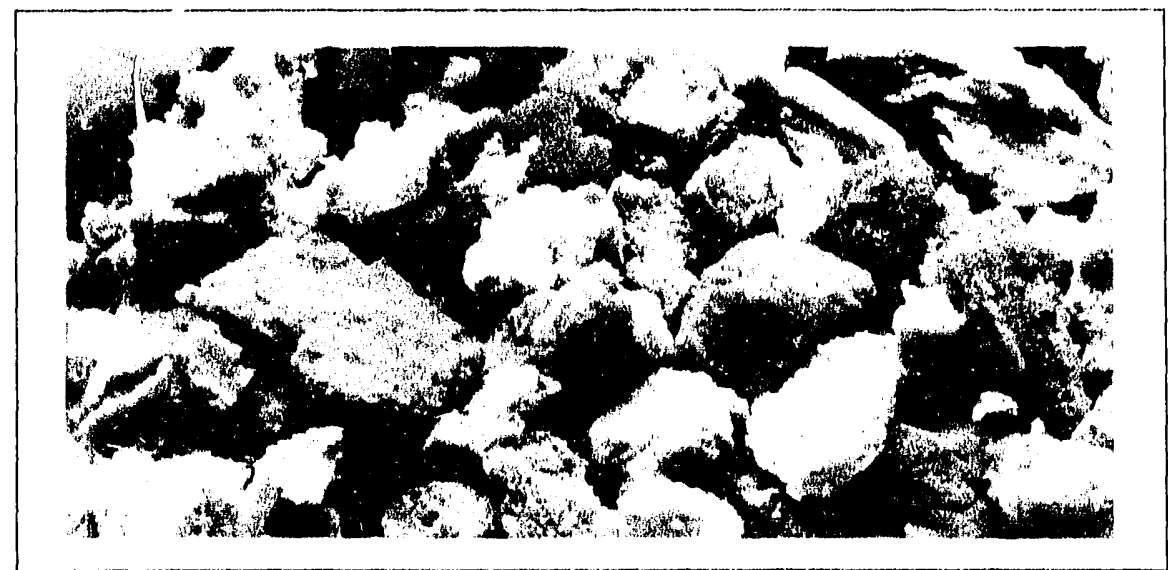

FIGURE 5 Recovered PUF after Cleaning 


\subsubsection{Extraction and Recovery of Plastics}

To extract the oils, the plastics-rich stream was treated first in the Soxhlet apparatus with acetone or hexane. The stream was then treated with EDC or THF, which extracted both ABS and PVC. This treatment was followed by a treatment with xylene to extract PP and any PE. The ABS/PVC extraction was about $6 \%$ of the mass of the initial shredder fluff sample, and the PP/PE extraction was a little over $2 \%$ of the mass of the initial sample.

The oil recovered from the PUF, the plastics-rich stream, and from washing the fines totaled about $9 \%$ of the shredder fluff mass. The oil contained some moisture because moisture is miscible with acetone and the shredder fluff was not dried before processing.

Figures 6 and 7 show the recovered ABS/PVC and PP/PE. The ABS/PVC sheet was made up of two distinct layers, one light brown and the other black. Because the layers were distinct, the two plastics were probably precipitated at different temperatures during the cooling cycle of the pregnant solvent. This phenomenon can be exploited by using a carefully controlled cooling process to separate the layers from each other, if necessary. However, PVC/ABS alloys are wellknown engineering plastics, and their separation may not be necessary. Infrared (IR) spectroscopy was used to identify the ABS and the PVC. Figures 8 and 9 show the IR spectra for the two plastics recovered from hand-picked samples of shredder fluff. In addition to enabling the identification of the plastics, these spectra show that the fluff had a low level of contamination, although those shredder fluff samples were not treated to remove oils, mud, and other contaminants. No attempt was made to identify the contaminants.

Although THF was able to dissolve PVC and ABS at a faster rate than EDC, we favored the use of EDC because THF is extremely flammable and has a tendency to form unstable peroxides, which limits its safe shelf life to only three months.

The PP/PE product shown in Figure 10 is black because of the presence of additives and plasticizers that are either soluble in the boiling xylene or small enough that they stay suspended in the solvent. When the PP/PE product was allowed to sit in xylene at room temperature, the xylene turned darker with time, while the PP/PE samples turned lighter, as shown in Figure 11.

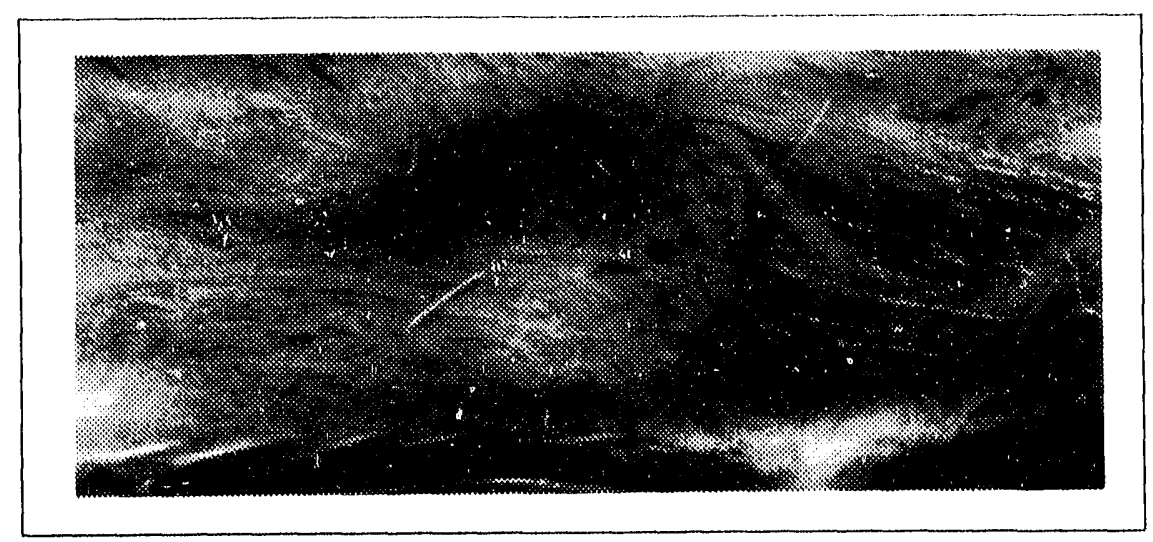

FIGURE 6 Recovered PVC/ABS 


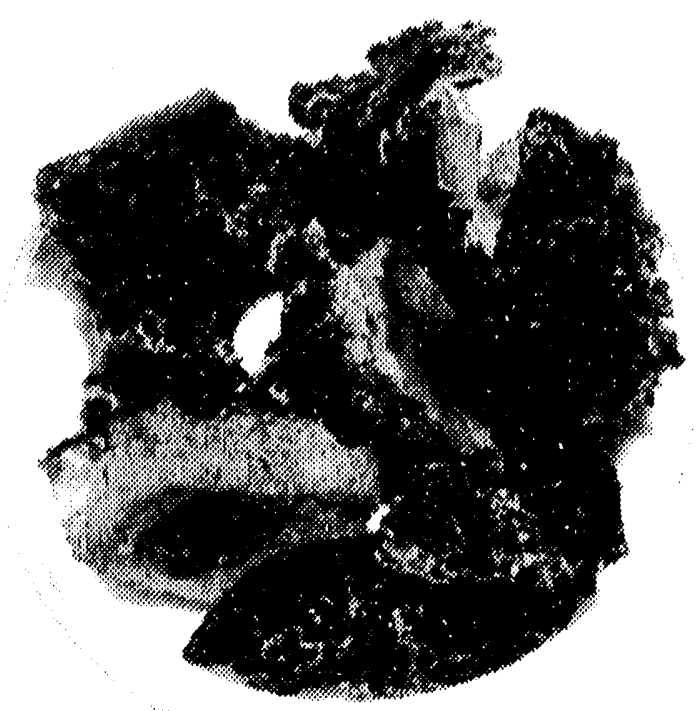

FIGURE 7 Polypropylene and Polyethylene Recovered from Fluff

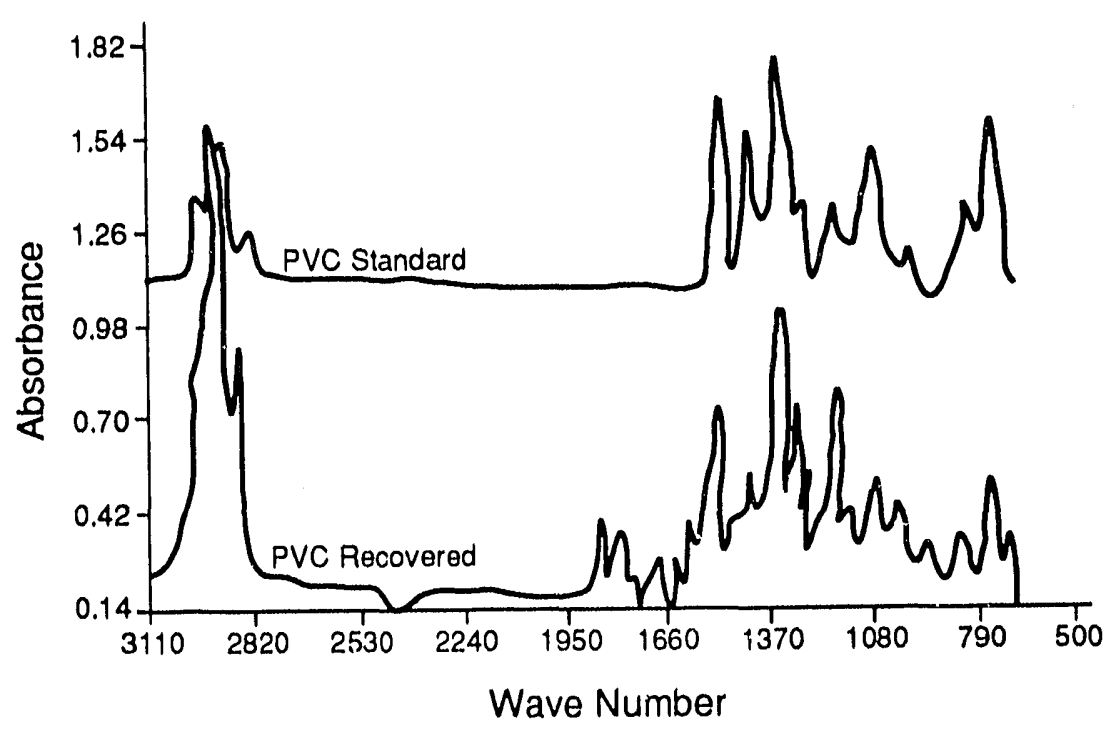

FIGURE 8 Infrared Spectra of Recovered PVC (bottom) Compared with Analytical-Grade PVC (top) 


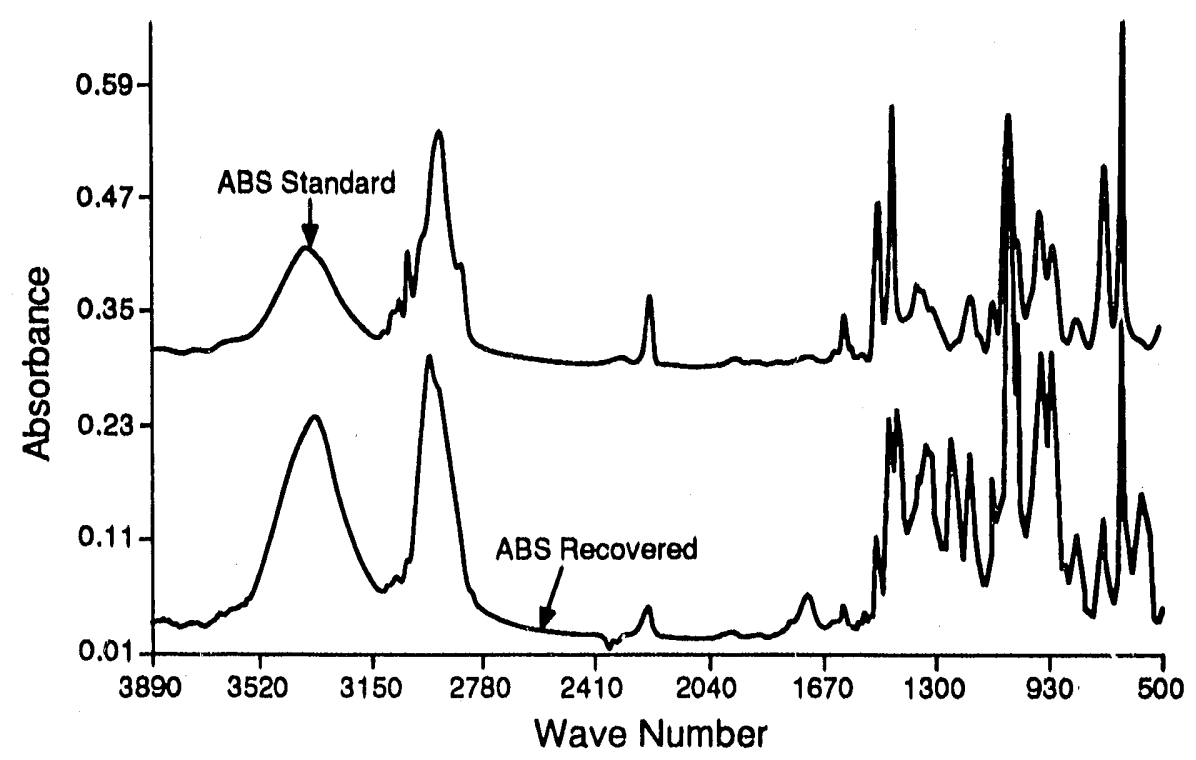

FIGURE 9 Infrared Spectra of Recovered ABS (bottom) Compared with Analytical-Grade ABS (top)

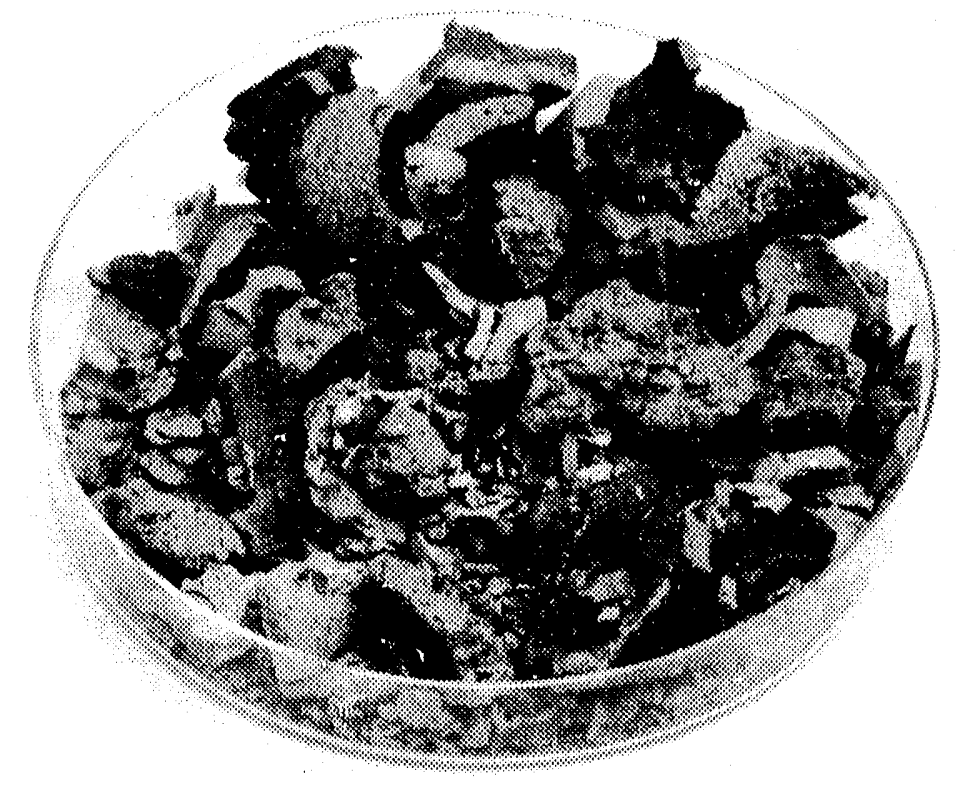

FIGURE 10 Partially Cleaned Polypropylene and Polyethylene Recovered from Flutt 


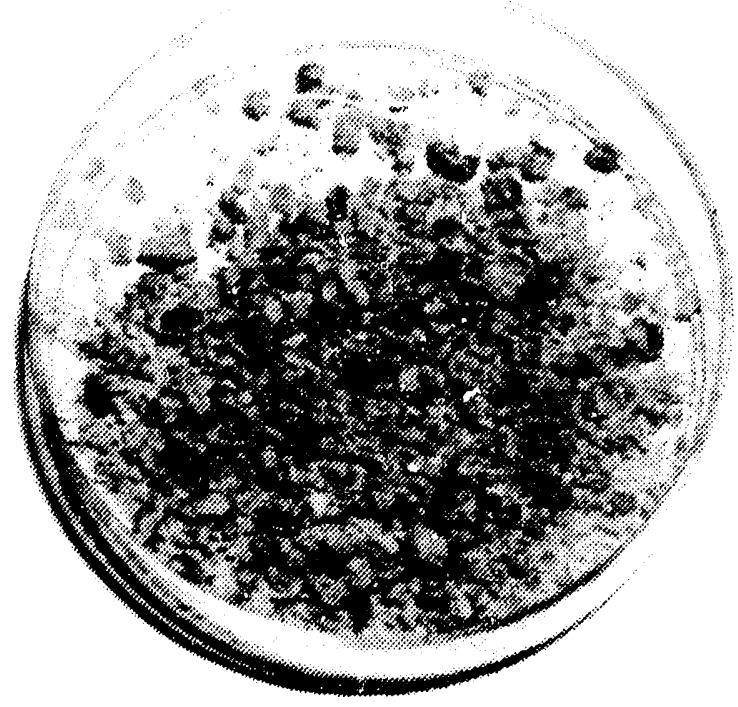

FIGURE 11 Cleaned and Filtered Polypropylene and Polyethylene Recovered from Fluff

Redissolution of the treated PP/PE samples in boiling xylene, pressure filtration of the solution while hot (around its boiling point), and then evaporation of the solvent yielded a granular PP/PE product that was light gray. We did not attempt to separate the small quantity of PE from the PP/PE mixture.

We also investigated the likelihood that the recovered plastics may contain metals. A PVC sample recovered from hand-picked shredder fluff from which metal fines were not screened was analyzed by using a scanning electron microscope (SEM). The SEM analysis showed that the PVC lacked metal contamination (Figure 12). The distinct chlorine peak in Figure 12 is further evidence that PVC was present.

\subsubsection{Solvent Recovery}

The solvents could not be completely evaporated, because otherwise the glassware would have been ruined. Nevertheless, we managed to recover about $74-92 \%$ of the solvents. Commercial-scale solvent-recovery systems are available that should recover in excess of $90 \%$ of the solvent. 

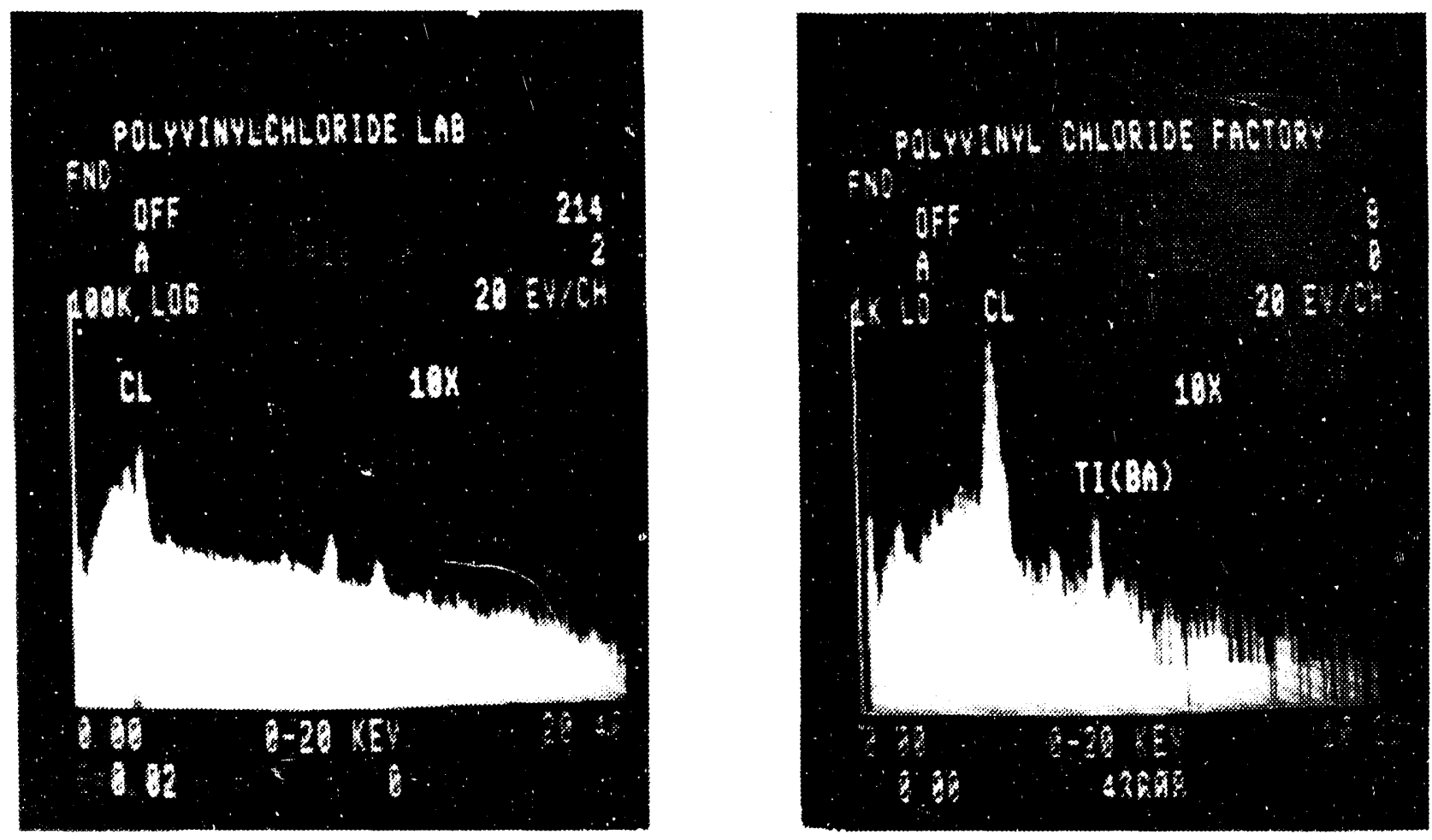

FIGURE 12 SEM Analysis of Recovered PVC 


\section{Discussion and Conclusions}

\subsection{Revised Concept for the Shredder-Fluff-Treatment Process}

The objective of the work presented in this repori was to determine the technical feasibility of selective dissolution and recovery of thermoplastics from shredder fluff. The results of the experiments confirmed the technical feasibility of the concept, and a process flow sheet was developed on the basis of the expected average composition of shredder fluff (Figure 13).

On the basis of $2 \times 10^{3} \mathrm{lb}$ of raw shredder-fluff feed with an average composition of $20 \%$ plastics, dissolution of the plastics is expected to yield about $120 \mathrm{lb}$ of recovered thermoplastics. Physical separation of the PUF and the fines prior to solvent extraction of selected plastics should yield about $130 \mathrm{lb}$ of PUF and $160 \mathrm{lb}$ of magnetic fines. Physical separation would yield a relatively homogeneous plastics-rich fraction of about $1.17 \times 10^{3} \mathrm{lb}$. Removal of the fines and PUF prior to solvent extraction would reduce the size of the reactor required for extraction because the PUF represents such a large volume of the shredder fluff. ${ }^{*}$ Removal of the fines would also reduce the possibility that the recovered plastics would be contaminated by metals.

After separation of the PUF and fines, the plastics-rich fraction would then be washed with a solvent (such as acetone) to remove the entrained automotive fluids that could contaminate the plastics that are subsequently recovered. We would expect that if PCBs are present in the shredder fluff, they would also be extracted with the oils and fluids. In addition, because water is miscible in acetone, a significant share of the moisture in the shredder fluff would also be extracted, if acetone were used as the solvent. Regeneration and recovery of the solvent would leave a concentrated, dry oil sludge that could have a high heating value (in excess of $16 \times 10^{3} \mathrm{Btu} / \mathrm{b}$ ), and it could be blended with the residue to produce a fuel pellet. Careful filtration of the dissolved oil solution may be necessary io avoid its contamination with heavy metals (such as lead).

On the basis of the energy and materials content of the input shredder fluff, the residual material (after extraction of the expected $120 \mathrm{lb}$ of plastics) would weigh about $10^{3} \mathrm{lb}$. This material, combined with the recovered oils from the shredder fluff, would have a total mass of about $1.1 \times 10^{3} \mathrm{lb}$ and would still contain about $5.1 \times 10^{6} \mathrm{Btu}$ of the $10.8 \times 10^{6} \mathrm{Btu}$ of the initial $2 \times 10^{3} \mathrm{lb}$ of raw shredder fluff. The residual material would therefore have an approximate fuel value of $4.6 \times 10^{3} \mathrm{Btu} / \mathrm{lb}$. Furthermore, because the PVC, the moisture, and fines would have been removed, the residual material would be more homogeneous than the raw shredder fluff and should have a low concentration of chlorine, moisture, and metals. Thus, the residual might provide a more acceptable supplemental fuel than would the raw shredder fluff.

\footnotetext{
* The amount of PUF that is present in the shredder fluff varies considerably and could be negligible for shredder fluff that has heen stored on-site for any period. Although PUF abounds in shredder fluff as it comes out of the shredder, anecdotal evidence indicates that the PUF is no longer present as foam in aged shredder tiutit. This phenomenon could be (at least partially) due to the hydrolysis of PUF in the presence of moisture at the elevated temperatures encountered inside the fluff piles.
} 


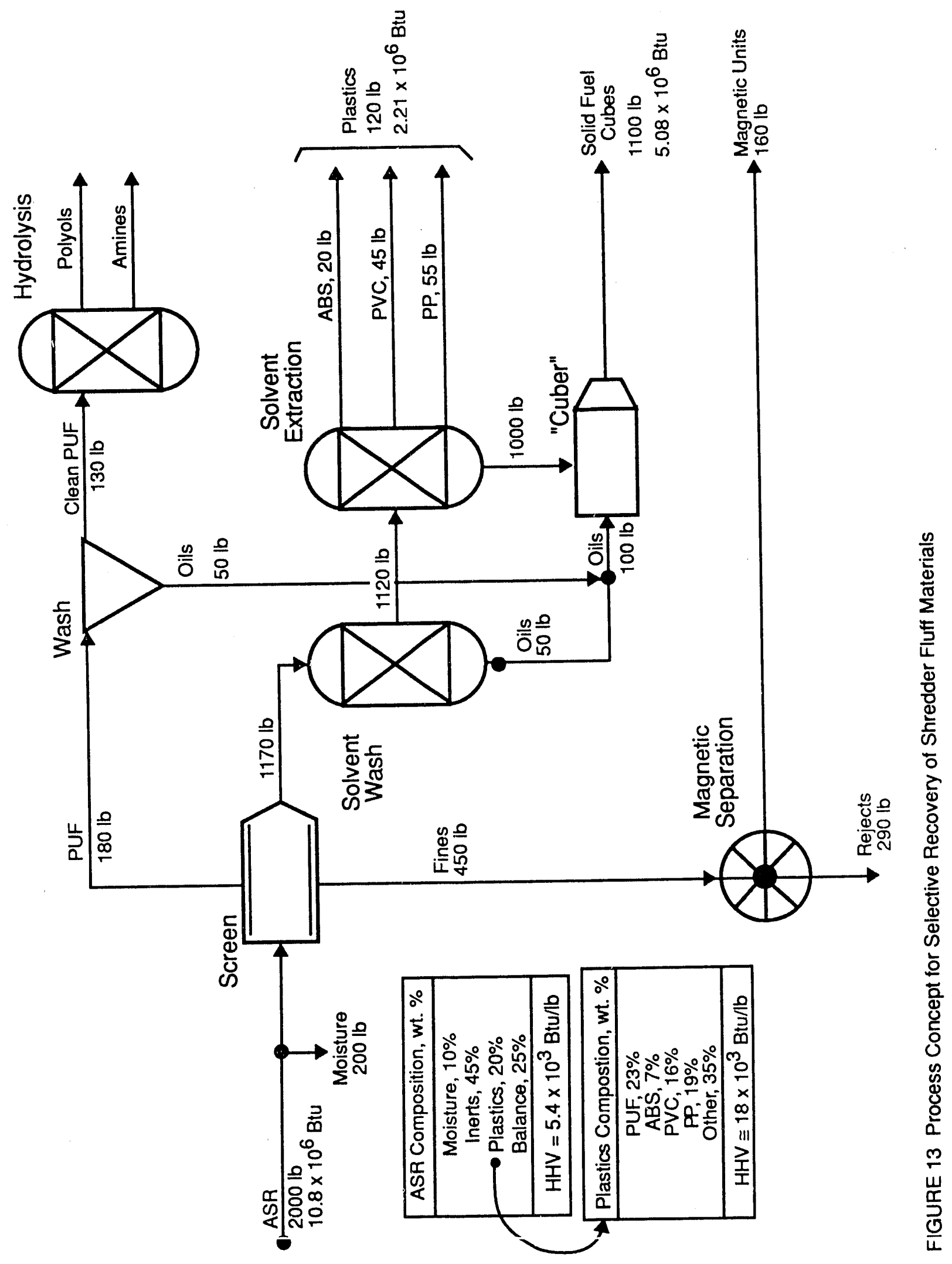


Magnetic separation of the fines from the shredder fluff would be expected to yield about $160 \mathrm{lb}$ of iron units, which might provide a feed similar to the iron units that were commonly recycled to sinter plants. Or, if the iron units were pelletized, they could provide a saleable iron unit for foundries. The dirty PUF recovered in the physical-separation step could be washed to produce a clean PUF that might be saleable as a raw material for carpet backing and/or provide a suitable feed material for hydrolysis to produce polyols and amines.

\subsection{Preliminary Process Economics}

Initially, we envisioned the selective extraction of plastics from shredder fluff as an alternative to other modes of recycling. If, however, the average composition of shredder fluff is indeed the average reported by the EnerGroup report (see appendix), this concept is not an alternative; it merely complements the other modes. The residual would still have a heating value, which would allow it to be used as a feed material for almost any of the other alternatives that have been considered for the recycling of shredder fluff. The distinction in this case is that the potentially high-valued plastics would have been recovered for reuse as plastics. Furthermore, because the material will have been physically screened, partially dried by the solvent-washing step, and stripped of the major chlorine-bearing material (the PVC), the residual should provide a more homogeneous feedstock for tertiary and quaternary recycling than the raw shredder fluff.

A preliminary estimate of the capital cost for a solvent extraction system (this estimate does not include ancillary processing, such as magnetic separation to upgrade the fines fraction, a cuber to produce consistent solid fuel pellets from the residual, or hydrolysis for conversion of the cleaned PUF) was derived on the basis of the capital cost estimate for a solvent-based coal-cleaning technology that is similar to the solvent extraction process proposed for the treatment of shredder fluff. This estimate is simply a factored estimate made on the basis of tons of material processed; therefore, it should be considered only as an order-of-magnitude estimate. On the basis of the data for solvent-based coal cleaning, the estimated capital cost of a facility processing $12 \times 10^{3}$ tons/yr of shredder fluff is about $\$ 750,000$. $^{*}$ On the basis of the expected content of plastics in the shredder fluff (ABS, PVC, PP, PE and PUF), the expected value of the recovered plastics might be as much as $\$ 65 /$ ton of shredder fluff processed. $\dagger$ This value would imply a payback for this technology in about one year. Anecdotal evidence suggests that, on the average, the assumption

does not appear unrealistic. Nonetheless, the actual value of the recovered material remains to be determined.

\footnotetext{
*Information is from the article by K.A. Roy, New Process Removes Sulfur from Coal Before Burning, 1990 , Hazmat World, 3(12):43-45, Dec. The described process uses perchloroethylene as a solvent to remove organically bound sulfur from coal. The process hardware presented in the article is expected to be quite similar to that which would be required for solvent extraction of plastics from shredder fluff.

†Chemical Marketing Reporter gives the following prices for plastics in its December 1990 issue: PE, $\$ 0.52 / 1 \mathrm{~b}$; PP, $\$ 0.50 / \mathrm{lb}$; PVC (pipe grade), $\$ 0.36 / \mathrm{lb}$; and ABS (pipe grade), $\$ 0.93 / \mathrm{lb}$. The values of PVC and ABS resins are about double the values given for pipe-grade counternarts. In its December 17, 1990, issue, Plastics News reported the following prices for "clean" recycled plastics: PP, $\$ 0.16-0.26 / \mathrm{lb}$; and PVC, $\$ 0.18-0.22 / \mathrm{b}$.
} 
A comparison of the capital cost (dollars per ton per year of shredder fluff) relative to the value of the recovered products (dollars per ton of shredder fluff) is summarized in Figure 14. Again, because none of the cost estimates are based on a detailed engineering design of the required facilities and the estimated values of the recovered products are not based on a detailed market study, the values and costs shown should be considered preliminary. Nonetheless, it appears that the more cost-effective options available for the recycling of shredder fluff are (1) the recovery of the plastics for reuse as plastics and (2) the production from the shredder fluff of a solid fuel pellet, which can be sold as supplemental fuel.

\subsection{Options for Recycling Automotive Plastics}

The focus of the work conducted at Argonne has been on the recovery of the thermoplastics content of obsolete automobiles after the auto hulk has been shredded to recover its metals. However, a considerable effort outside of Argonne has focused on the recovery of potentially recyclable plastics from the obsolete automobile by the auto dismantler prior to shredding the hulk. The result of this approach would be a recovered plastic with less contamination (contamination in the sense of materials that would affect the quality of the recovered plastics) than that yielded by solvent dissolution and recovery from the shredder fluff.

Recovery of the plastics prior to shredding appears to imply a greater likelihood that the plastic can be recycled. This may not be the case. For example, some auto dismantlers in the United States have removed plastic components (such as those in bumpers), only to be told by potential plastics recyclers that the material is unacceptable because of the paint on the plastic and the presence of adhesives that were used to "weld" the plastic components of the bumpers together. Attempts by dismantlers to physically remove the adhesive layers have been unsuccessful. We would expect that even when the plastic component is stripped by a dismantler, some form of processing for cleaning up the plastic will be required. At this point, it is not clear whether it is more cost-effective to remove and clean the component for recycling prior to shredding than it is to extract the plastic from the shredder fluff after shredding. We suspect that both approaches might be required to achieve a least-cost alternative for the recycling of automotive plastics.

\subsection{Conclusions}

A cost-effective solution to the problem of rapidly escalating costs of disposing of shredder fluff is essential to the long-term viability of the auto shredder industry and to the continued recovery and recycling of the metals content of obsolete automobiles. A number of technological alternatives have been considered in the past, although these options have focused on the conversion of the shredder fluff to fuels and chemicals or on incineration with heat recovery to produce steam or electricity. Moreover, these options have not proven to be cost-effective and are, for the most part, capital-intensive. 


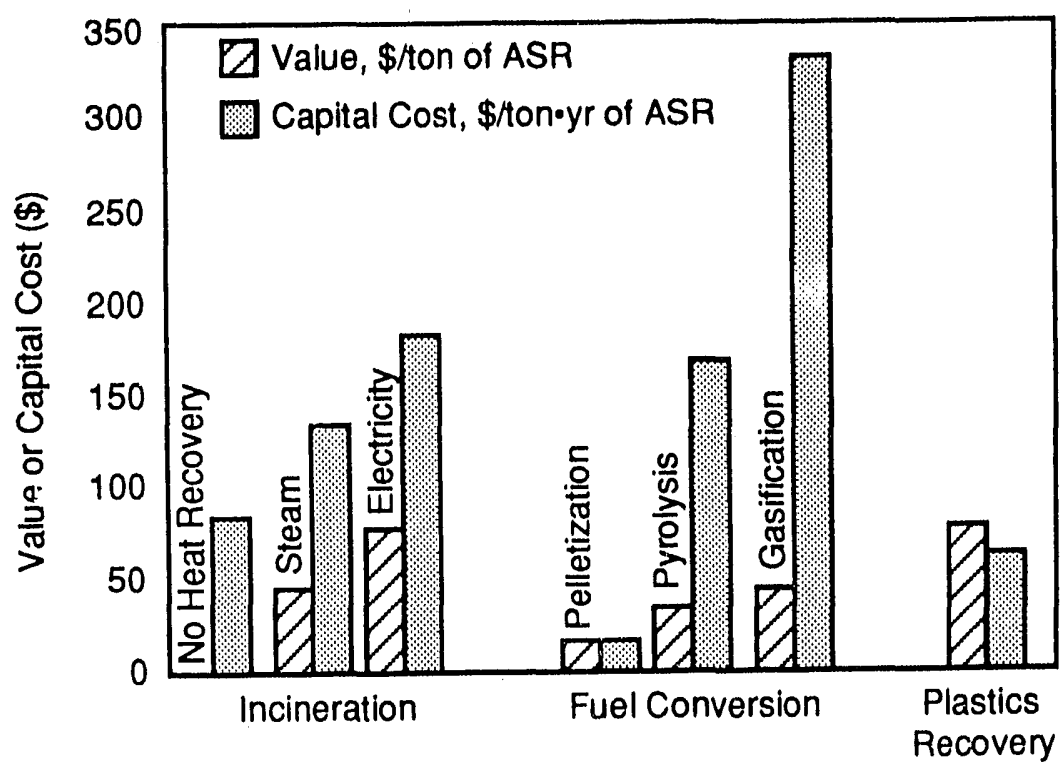

FIGURE 14 Relative Value of Shredder Fluff Compared with Expected Unit Capital Cost for Alternative Recycling Modes

Notes to Figure 14:

a. Values are the expected market value of the recycled shredder fluff in dollars per ton of shredder fluff. Capital costs are based on dollars per ton per year of shredder fluff processed, assuming a plant design capacity based on $7,884 \mathrm{~h} / \mathrm{yr}$. For example, an incinerator with a plant design capacity of $12 \times 10^{3}$ tons/yr of shredder fluff operating at $7,884 \mathrm{~h} / \mathrm{yr}$ is estimated to have a capital cost of $\$ 1$ million, which equates to a capital cost of $\$ 83$ ton $\cdot y r$. Operating and maintenance costs are not considered in any of the options depicted in the graph.

b. The values of the shredder fluff do not include any credit for the reduction in landfill costs associated with each alternative. Regardless of the alternative, the ash content of the shredder fluff remains unchanged. Consequently, the amount of material that would remain to be landfilled, for each option, is essentially the same. We would expect that the cost of landfill, if it is not borne directly by the shredder, would otherwise be reflected in the market value of the product derived from the shredder fluff.

c. Incineration without heat recovery yields no value for shredder fluff other than the savings in landfall costs. As such, the value of the this option is zero, as depicted in the graph.

d. The fuel value of the shredder fluff is taken at $5.4 \times 10^{3} \mathrm{Btu} / \mathrm{lb}$ (higher heating value, HHV). The ash content is taken at $50 \%$ by weight.

e. Conversion to steam is taken at $85 \%$ of the HHV. Steam energy content is taken at $10^{3} \mathrm{Btu} / \mathrm{lb}$, with a steam value of $\$ 5 / 10^{3} \mathrm{lb}$. 
Notes to Figure 14: (Cont'd)

f. Conversion to electricity is taken at $30 \%$ of the HHV. Electricity is valued at $\$ 0.08 / \mathrm{kWh}$.

g. Solid fuel pellets are assumed to have a market value of $\$ 1.50 / 10^{6}$ Btu.

h. Conversion of the shredder fluff via pyrolysis is assumed to have a $75 \%$ yield of liquid fuels (at $125 \times 10^{3} \mathrm{Btu} / \mathrm{gal}$ ). In other words, $75 \%$ of the HHV of the shredder fluff is converted to saleable liquid fuels. The market value of the liquid fuel is taken at $\$ 0.75 / \mathrm{gal}$.

i. Conversion of the shredder flutf via gasification is assumed to have a $50 \%$ yield of gaseous fuels on the basis of the HHV of the shredder fluff. The value of the gas is taken at $\$ 5 / 10^{6} \mathrm{Btu}$.

j. The value of the plastics is based on a $90 \%$ recovery of the expected ABS, PVC, and PP and an assumed value of $\$ 1 / 1 \mathrm{~b}$, $\$ 0.25 / \mathrm{b}$, and $\$ 0.05 / \mathrm{lb}$, respectively. Recovered PUF, also taken at $90 \%$ of the expected PUF content, is valued at $\$ 0.25 / \mathrm{lb}$.

Argonne National Laboratory has conducted an initial research effort focused on the selective recovery of some of the thermoplastics from shredder fluff for the potential recycling of these materials as plastics. Because the use of automotive plastics is expected to increase and the market for recycled plastics is growing, this approach is appealing.

Research that has been conducted confirms the technical feasibility of selectively extracting certain thermoplastics from shredder fluff. Although the process may be technically feasible for the recovery of plastics, the problem that must ultimately be addressed is cost-effectiveness. The solution to this problem depends on two critical issues: processing costs and market values of the recovered products. These issues are the subject of continuing process-development research. 


\title{
Appendix: \\ Automobile Shredder Residue: Treatment Options
}

\author{
by \\ B.J. Jody and E.J. Daniels \\ Energy Systems Division \\ Argonne National Laboratory \\ 9700 South Cass Avenue, Argonne, Illinois 60439 \\ submitted for publication in \\ Hazardous Waste and Hazardous Materials
}




\title{
Automobile Shredder Residue: Treatment Options"
}

\begin{abstract}
The single largest source of recycled ferrous scrap for the iron and steel industry is obsolete automobiles. The process of recovering reusable metals from obsolete automobiles leaves the automobile shredder operator with nonmetallic shredder residue, termed "fluff," that must be disposed of. The disposal cost affects the viability of the automobile shredder industry and, in turn, the supply and price of high-quality scrap for the iron and steel industry. Rising disposal costs are further exacerbated in that the percentage of fluff that must be disposed of, compared with the percentage of marketable recovered metals, is increasing because of the increasing content of plastics in automobiles. Argonne National Laboratory, in cooperation with the Institute of Scrap Recycling Industries, is systematically assessing alternatives for recycling fluff. The objective is to reduce the escalating costs of metals recycling. In the absence of a commercially viable automobile shredder industry, the outcome would be increased environmental insult and a decreased supply of quality scrap, which would result in the production of finished metals from primary ores. This paper discusses the available technologies for the treatment of fluff.
\end{abstract}

\section{A.1 Introduction}

In 1988, the automobile shredder industry supplied in excess of $10 \times 10^{6}$ tons of recovered ferrous scrap for use in the iron and steel industry. The single largest source of that raw material was obsolete automobiles, although other source materials (such as refrigerators, washing machines, and other appliances that are commonly referred to as "white goods") also contributed to the supply of recovered metals. In the process of recovering the marketable metals components from obsolete materials, the shredder industry was left with about $2.5 \times 10^{6}$ tons of residual that must be disposed of. The most common method of disposal at present is to landfill the fluff. However, the cost of landfilling has increased dramatically over the past few years, and state and local governments are banning landfills. Without a viable alternative for the treatment of fluff, the level of metals recycling will undoubtedly decrease because of increasing operating costs. The impact of these costs will also be exacerbated by the increasing content of plastics used in automobiles. For example, in 1960, the average automobile weighed approximately $3,800 \mathrm{lb}$ and contained less than $40 \mathrm{lb}$ of plastics. By 1980, the weight of the average automobile had decreased to about 3,200 lb, which included approximately $175 \mathrm{lb}$ of plastics. By 2000, the average automobile is expected to weigh about $3,000 \mathrm{lb}$ and contain $400 \mathrm{lb}$ of plastics.

\footnotetext{
* This work was supported by the U.S. Department of Energy, Assistant Secretary for Conservation and Renewable Energy, under Contract No. W-31-109-Eng-38.
} 
The composition of the fluff varies, even in a given facility, because different types of source materials and different models and years of obsolete automobiles are shredded (Plastics Institute of America, 1987a). Typically, the fluff contains plastics, rubber, fibers, fabrics, paper, glass, wood, tar, dirt, rocks, sand, oil, moisture, and small amourits of metals that are not recovered in the shredding operation. Approximately $40-50 \%$ of the fluff is combustible material, which is essentially hydrocarbon-based compounds (such as plastics, fibers, wood, and rubber). The heating value of fluff may vary from approximately 4,000 to $6,000 \mathrm{Btu} / \mathrm{lb}$ and average approximately 5,400 Btu/lb (Hubble, Most, and Wolman, 1987). The plastics content of fluff is approximately $15-30 \%$ by weight. However, the newer automobiles that will be shredded in the future are expected to contain as much as $25-50 \%$ more plastics by weight. Within $10-15 \mathrm{yr}$, the metals recovered relative to the quantity of fluff may decrease from about $4: 1$ by weight to as low as $3: 1$ by weight.

Many types of plastics are present in fluff, including polyurethane foam, acrylonitrile butadiene (ABS), polypropylene, low- and high-density polyethylene, nylons, polystyrene, polyvinylchloride (PVC), and glass-reinforced polyester.

Because of the content of plastics and other combustibles in fluff, it can technically be considered for all four generic recycling options (primary, secondary, tertiary, and quaternary) and for incineration for weight and volume reduction without energy recovery.

\section{A.2 Background}

Prior to the introduction of the automobile shredder in the early $1960 \mathrm{~s}$, the most common method of recycling obsolete automobiles involved open-air combustion of the automobile hulk to burn off plastics and other combustibles. Open burning is no longer practiced because it is a gross violation of environmental (Clean Air Act) regulations. More controlled incineration techniques were explored in the late 1950s and early 1960s (Dean et al. 1985; Bilbrey, Stemer, and Veldez 1979; Ellsworth, Ballinger, and Engdahl 1957).

With the introduction of the shredder and the incorporation of better separation techniques (such as multiple magnetic separation stages, air classification, screens, and wet and dry cyclones in the early 1960s [Dean et al. 1985]), the number of obsolete automobiles processed increased dramatically and so did the amount of recovered metals. Several publications that appeared in the late 1960s and early 1970s addressed a variety of topics on the subject, including the production of quality scrap, improved separation methods, the impact of increasing plastics content of automobiles, process economics, and environmental concerns associated with the process (Kaiser and Tolciss 1961; Dean and Sterner 1969; Adams 1972; Luntz 1973; Dean, Sterner, and Valdez 1974; Daellenbach, Mahan, and Drost 1974; Scrap Age 1974; Sawyer 1974). The 1970s also brought an increased public interest in the processing and recycling of plastics waste (Sterner, Steele, and Shirts 1984; Warner, Parker, and Baum 1970; Mack 1971; Leidner 1981). This interest was stimulated primarily by (1) increased public awareness of the magnitude of the plastics waste problem in general and (2) increased disposal costs. During the 1970s, two methods of fluff disposal were practiced: landfilling and incineration. 
Landfilling continues to be the most widely practiced disposal techrinue for fluff. Landfilling of fluff may soon be a cost-prohibitive technique in many parts of the country or banned altogether. Many states already require treatment of the fluff to fix and immobilize heavy metals before landfilling. For some shredder operators, almost $50 \%$ of their operating costs in 1989 were attributed to fluff disposal. Because disposal costs continue to escalate, more economical alternatives need to be developed.

Incineration could be a cost-effective technique to dispose of fluff because its heating value is nearly half that of coal; consequently, fluff will burn without the need for supplemental fuel. Several studies addressed this topic, and many full-scale fluff incinerators were built by scrap processors (Hubble, Most, and Wolman 1987; Dean et al. 1985; Bilbrey, Sterner, ind Valdez 1979; Ellsworth, Ballinger, and Engdahl 1957; Bilbrey, Dean, and Sterner 1974). Dean et al. (1985) estimated that at least 23 such units were built by the end of 1973. To the best of our knowledge, none of these units are in operation today, although incineration can achieve more than a $50 \%$ reduction in the weight and over a $75 \%$ reduction in the volume of fluff. This lack of acceptance of incineration is due to a combination of economic, environmental, and logistic problems, among which are the following:

1. Landfilling is still less expensive than incineration in most locations, and

2. Gas scrubbers are required because fluff contains chlorine and sulfur.

Although the technology for scrubbing $\mathrm{HC} 1$ and $\mathrm{SO}_{\mathrm{x}}$ exists, scrubbing of these compounds is expensive, especially when they are present in high concentrations, which may be the case for fluff. Hubble, Most, and Wolman (1987) reported chlorine concentrations as high as $16.9 \%$ (the average concentration was $3.4 \%$ ) on the basis of samples from 12 shredding sites. Moreover, the high chlorine content, in particular, will make the flue gas very corrosive, which will increase the materials and maintenance costs of the incinerator.

Chlorine is also suspected of increasing the risk of producing dioxins and benzofurans during the combustion process (Hubble, Most, and Wolman 1987). Therefore, we anticipate that the operation of incinerators will be subject to a complicated permitting process that may call for excessive and costly chemical analysis. Incineration is even more expensive if the fluff contains polychlorinated biphenyls (PCBs). Governing regulations require that $\mathrm{PCBs}$ be incinerated at very high temperatures (about $2,000^{\circ} \mathrm{F}$ ). High-temperature incinerators are very costly to build and maintain. Supplementary fuel might also be required to attain such temperatures, which, of course, increases operating costs. Moreover, the location of incineration facilities can be challenged by the Not in My Backyard (NIMBY) syndrome, which further complicates the permitting process.

The cost-effectiveness of incineration depends on the site and on the variability of the composition of the fluff, local landfill costs, heavy metai composition, and the type of incinerator. Woodruff, Mechel, and Albertson of Energy Products of Idaho (1990) claim that "preliminary results of one and one-half years of pilot plant test work indicate that the fluidized bed combustion process does offer an economical alternative for the disposal of automobile shredder residue." 


\section{A.3 Recycling}

Because fluff has a high hydrocarbon and plastics content, it can conceptually be recycled by primary, secondary, tertiary, and quaternary modes. With respect to fluff recycling, secondary and quaternary recycling have been emphasized. The applicability of these recycling procedures to fluff is discussed below.

\section{A.3.1 Primary Recycling}

Primary recycling generally refers to the recycling of uncontaminated waste material within the industrial manufacturing sector. Primary recycling could also apply to the separation of individual components within fluff, with the intention of using those components as a blend with virgin inaterial.

Dean et al. (1985) reported on a set of experiments conducted by the U.S. Bureau of Mines in which heavy-medium separation of the individual plastics in fluff was attempted. In these experiments, the float and middling fractions from a water elutriator were sent to a gravity plastics separator comprised of a series of brine cells, each maintained at a different specific gravity. Although $100 \%$ separation was not achieved, the tests showed that certain plastics could be concentrated in the various fractions (see Table A.1). Conceptually, concentrating the various fractions of fluff might improve the viability of any recycling opportunity, although heavy-medium separation may not necessarily be the best method.

A process that may be applied to separate and recycle the plastics in fluff is via the use of solvents. Because this method involves solvents and chemical processing, we discuss it under tertiary recycling.

TABLE A.1 Results of Heavy-Medium Separation Test

Type of Plastic in Fraction (weight \%)

\begin{tabular}{rrrrrrrr} 
Fraction & ABS & Acrylic & PE & PP & PVC & Rubber & Other \\
\hline & & & & & & & \\
1 & 0 & 0 & 5.4 & 67.0 & 2.0 & 18.6 & 7.0 \\
2 & 69.5 & 1.2 & 0.5 & 0 & 4.5 & 2.6 & 20.2 \\
3 & 48.5 & 1.1 & 0 & 0 & 5.7 & 20.1 & 20.1 \\
4 & 0 & 34.9 & 0 & 0 & 3.3 & 31.9 & 27.0 \\
Sink & 0 & 0 & 0 & 0 & 16.5 & 50.5 & 12.9
\end{tabular}

Source: Dean et al. 1985. 


\section{A.3.2 Secondary Recycling}

The most comprehensive research regarding secondary recycling of fluff was that funded by the Energy Conversion and Utilization Technologies (ECUT) branch of the U.S. Department of Energy (Plastics Institute of America 1987a, 1987b, 1980; DOE/ECUT and PIA 1984; Curlee 1986; MSREF 1983). Production of secondary products from fluff has been pursued because of the thermoplastics content of the fluff. Thermoplastics represent approximately $70-80 \%$ of the total plastics in fluff, and thermoplastics can be heated and remolded into different products. Products such as park benches, lamp posts, road traffic furniture, shingles, and other construction materials can be made from wastes containing plastics by using state-of-the-art extrusion and molding equipment. Sixty-four such products were identified, and these products are listed in Table 2 of Hubble, Most, and Wolman (1987). The presence of hard objects in the waste material (such as gravel, metals, and glass) could, however, damage the molding equipment and/or increase its maintenance cost.

The key limitations of this type of recycling are (1) the market for such products is small and (2) the cost of making such secondary products is not insignificant. As a result, secondary products are, at best, only marginally competitive with their counterparts that are made of virgin materials (such as wood, sand, and gravel).

Factors that are of consideration in secondary recycling are:

1. Fluff contains heavy metals that should be locked in the product once the plastics are melted and remolded. However, many plastics teand to degrade slowly in an acidic or basic medium. Oil, PCBs, and other organics that may be present in the fluff could also become exposed and leachable.

2. The quality of products that can be derived from fluff can be upgraded by partial separation of undesired components (such as glass, metals, and gravel) and by the addition of virgin plastics and other additives (Plastics Institute of America 1987a, 1980). The appeararce of the product can also be enhanced by sandwiching the recycled material between thin layers of virgin material.

3. The continuously changing composition of fluff demands that plenty of tolerances be provided for in the design of the process in order to regularly meet product specifications and prevent obsolescence.

The increasing plastics content of cars could make fluff more suitable in the future for making secondary products. However, it is our belief that such products will continue to be difficult to market because they are more expensive than conventional products.

Equinment that has heen developed or is under development for the secondary recycling of plastics in municipal solid waste streams could be adopted for the secondary recycling of fluff. This equipment includes Mitsubishi's Revezer ${ }^{\mathrm{TM}}$, the Klobbie ${ }^{\mathrm{TM}}$, the FN ${ }^{\mathrm{TM}}$ machine, the Flita System $^{\mathrm{TM}}$, the Remaker ${ }^{\mathrm{TM}}$, the Regal Converter ${ }^{\mathrm{TM}}$, and Kabor's $\mathrm{K}^{\mathrm{TM}}$ board. 
The ECUT work also evaluated the use of fluff as an additive for "polymer concrete." In general, the conclusions appear to indicate a lower compressive s'rength for the fluff-polymer concrete.

Boeger and Braton (1990) report on another concept for fluff in which it would be physically separated into three fractions: metals, mill fuel, and mill cover. The mill cover is the nonmetallic fraction under two inches, and it is being tested as a landfill cover. The fraction greater than two inches is reported to have a calorific value of almost $11,000 \mathrm{Btu} / \mathrm{b}$ and could conceptually be used as a fuel for quaternary recycling.

\section{A.3.3 Tertiary Recycling}

Tertiary recycling or chemical processing could be used to produce value-added products (such as monomers, solvents, light hydrocarbons, and/or liquid and gaseous fuels) from the hydrocarbon-based fraction of fluff (plastics, rubber, paper, and wood) (Plastics Institute of America 1987a; Leidner 1981; Curlee 1986; Braslaw and Gerlock 1984; Mahoney, Weiner, and Farris 1974; Dean, Chindgren, and Valdez 1972; Banks, Lusk, and Ottinger 1971; Huang and Dalton 1975). Plastics, however, will be the main source for such products. Processes that may be employed for this purpose include the following:

- Pyrolysis,

- Hydrolysis,

- Selective dissolution,

- Hydrogenation, and

- Gasification.

Pyrolysis, the thermal decomposition of organic material in an oxygen-deficient environment, is a well-known technique for the production of fuels and chemicals from feedstocks such as wood, coal, tires, and municipal waste. The type and relative quantities of different products are generally a function of the operating conditions, primarily temperature. This property enables the operator to change the product mix should market prospects change. The applicability of pyrolysis to plastics has also been demonstrated. Banks, Lusk, and Ottinger (1971) reported that the major products of this process from the use of polyethylene as a feedstock were hydrogen, benzene, methane, ethylene, and propane; the major products from the use of polyvinylchloride were benzene, acetylene, styrene, and hydrogen-chloride; and the major products from the use of polystyrene were styrene, benzene, toluene, and methylstyrene.

With the exception of one tire-pyroiysis unit operating in Ôdesto, Caiifornia, which uses the fuels produced for the production of electricity for sale back to the utility, no commercial-scale pyrolysis reactors are in operation. To the best of our knowledge, no data are reported on the 
pyrolysis of fluff. However, it is our understanding that some limited testing has been done. We have no knowledge of the results of these tests at present.

We would anticipate that pyrolysis of fluff would yield products similar to those produced by the pyrolysis of polyethylene, polyvinylchloride, and polypropylene. More work is required to establish the operating conditions necessary for the production of a desired product mix. We would expect that the variability of the composition of the fluff might present a control problem for the system.

According to Leidner (1981), some of the problems that were encountered in pyrolyzing plastics containing materials are as follows:

1. Pyrolysis of plastics requires more time than pyrolysis of other hydrocarbons because of the poor heat-transfer characteristics of the plastics.

2. Carbon residue produced by plastics pyrolysis has a tendency to stick to the walls of the reactor.

3. Some plastics, when heated, produce a high-viscosity material that is difficult to pump.

Hydrolysis involves reactions with water (generally at elevated temperatures) and is widely practiced in the chemical industry. Its applicability to fluff has been investigated primarily for the treatment of the polyurethane foam (PUF) (Braslaw and Gerlock 1984; Mahoney, Weiner, and Farris 1974; Valdez, Dean, and Bilbrey 1975). It is also applicable to the treatment of polyesters, polycarbonates, and polyamides. Mahoney, Weiner, and Farris (1974) of Ford Motor Co. showed that the hydrolysis of polyurethane foam produces two main products: polyols and amines. Braslaw and Gerlock (1984), also of Ford, developed a process to separate and purify the product mix to produce very high-quality polyols. Experiments reported by Braslaw and Gerlock (1984) used (separately) clean foam as a material input to the process and "as-received" foam from a shredder. They then tested the physical properties of their seat-foam formulation by blending the recovered polyols with virgin material. A blend with up to $50 \%$ of the polyols recovered from the clean foam waste produced a foam with physical properties not "significantly different" from those of all-virgin foam. When the polyols from the "as-received" foam were blended, physical properties consistent with all-virgin foam were achieved with less than $10 \%$ of the recovered polyols. Braslaw and Gerlock (1984) estimated a $\$ 275,000$ after-tax cash flow on a $\$ 1.1$ million plant operating one shift per day with an annual capacity of about 1,000 tons per shift. Braslaw and Gerlock also pointed out that the technology would only be applicable for processing dirty PUF because there is a market for clean industrial PUF waste among carpet underlay manufacturers. When the market value of the clean foam is taken as an operating cost for the process, the positive cash flow becomes negative.

Selective dissolution of plastics from a mixed-plastic stream by using solvents is a iechininique thât could to ussed io recover plastics in a usable form that might qualify for primary recycling (Plastics Institute of America 1980; Tesoro 1987; Lynch and Nauman 1989). Solvent specification and operating temperatures, both for dissolution and separation, are essential to 
produce high-purity products that can be substituted for or mixed with virgin materials without reducing the quality of the final product (DuBois and John 1967). Lynch and Nauman (1989), under a grant from the New York State Energy Research and Development Authority and the Center for Plastics Research, have conducted experiments using solvents to dissolve plastics from a mixed stream followed by flash devolatilization to effect separation of the solvent from the dissolved plastic.

To the best of our knowledge, this technique has not been investigated for processing fluff, except for the work we are conducting at Argonne National Laboratory (ANL) (Jody et al. 1990). The approach emphasized at ANL is to use several solvents to extract individual plastics, one at a time when possible. For instance, a solvent such as acetone or hexane can be used to remove oils and some of the plasticizers from the fluff. Treatment with xylene at room temperature can dissolve the polystyrene. Treatment with tetrahydrofuran or dichloroethane dissolves the polyvinylchloride and the ABS. Treatment with xylene at elevated temperatures can extract polyethylene and polypropylene. An interpretation of the data generated to date at ANL and of that provided by Lynch and Nauman (1989) could lead to a procedure that uses aspects of both techniques for separation and purification of individual plastics, subject to the market value and quality of the plastics.

Hydrogenation of the fluff can also be used to remove chlorine and sulfur and produce more saturated hydrocarbons. However, hydrogenation processes are generally carried out under high pressures and elevated temperatures. Another advantage of hydrogenation in this application is that the metal compounds present may be reduced to their elemental state, which makes them more recoverable. The cost of hydrogen needs to be considered carefully in this case because it may be substantial.

Gasification could also be used to convert the hydrocarbon material in the fluff into a lowBtu gas containing carbon monoxide, hydrogen, and other light hydrocarbons. The product gas can be used as either a gaseous fuel or a feedstock to produce liquid products, such as methanol.

A high-temperature gasification test was conducted by using the gasifier developed by VOEST-ALPINE Industrienlagenbau, Ges.m.b.H, of Austria (see Appendix E of Schmitt 1990). In the gasification tests, the fluff was blended with mixed plastics, waste oils, and fuel oil. The net calorific value of the blended material was about $17,000 \mathrm{Btu} / \mathrm{lb}$, which would indicate that the amount of actual fluff used relative to the oils and mixed plastics was approximately $25 \%$. Analysis of the products resulting from gasification showed that several dioxin species were present in minute quantities. The product gas, which consisted of nitrogen $(58 \%)$, hydrogen $(12.7 \%)$, carbon monoxide $(17 \%)$, carbon dioxide $(5 \%)$, with the balance water vapor, had a calorific value of about $100 \mathrm{Btu} / \mathrm{ft}^{3}$. This product would be considered a low-Btu industrial fuel gas.

\section{A.3.4 Quaternary Recycling}

Quaternary recycling is the recovery of the energy value of the waste via incineration, with heat recovery from the combustion gases to produce steam or steam and/or electricity. 
In a recent study sponsored by the U.S. Department of Energy, the potential of harvesting some of the energy released in the incineration process was evaluated (Hubble, Most, and Wolman 1987). During field tests, samples of fluff from 12 different facilities were burned in a rotary kiln incinerator. Different scenarios for using the released thermal energy were also analyzed. The major findings of the study are summarized and discussed below.

1. The average heating value of the fluff material is about $5,400 \mathrm{Btu} / \mathrm{lb}$.

2. The chlorine content of the fluff samples varied between 0.7 and $16.9 \mathrm{wt} \%$. This large variation is likely to result in an overdesigned scrubbing system in order to comply with the worst-case scenario.

3. The moisture content of the samples varied between 2 and 34 wt\%. The water in the fluff will consume a substantial portion of the heat released in the incineration process, which will result in a lower flame temperature than could otherwise be obtained. As a result, the availability of useful energy is reduced. Water in the fluff will also lower the dew point of the flue-gas stream. This lower dew point will increase the chance that condensation will occur during the heat-recovery process. Condensation will be detrimental to the duct work because of the highly corrosive nature of the flue gas. The study demonstrated that the flue gas can be scrubbed to comply with governing environmental regulations using state-of-the-art equipment.

4. The ash remaining after incineration is about $25-72 \mathrm{wt} \%$ of the starting material (average value is about $44 \mathrm{wt} \%$ ). This proportion of ash about doubles the concentration of metals in the ash; as a result, the ash could be classified as hazardous, which would then require fixing and/or postprocessing the ash for recovery of the metals. For example, it was reported in the CMP report (Schmitt 1990) that Puremet Corporation has developed a hydrometallurgical process that would be applicable for the recovery of the metals from fluff incinerator ash.

5. When the heat is used to produce steam, the amount of steam generated as a result of incinerating the fluff material far exceeds the on-site heat requirements. Therefore, unless there is a customer for the heat nearby, the heat will be uneconomical to recover and transport to the customer.

6. On-site electricity generation was also evaluated. In general, the amount of electricity that could be produced from the fluff available at most shredders exceeds the on-site electricity requirements of the shredder, and this excess electricity can be sold back to the utility. The sale of electricity depends on many factors, including compliance with Public Utility and Regulatory Policy Agency (PURPA) requirements in order to qualify as a cogenerator. The economic competitiveness of such a venture will also depend on many other factors, including the cost of electricity, the rate at which the local utiliiy wili purchase excess electricity, and the consistency of fluff production rates, which 
will affect the design of the equipment relative to its utilization. Under the assumptions of the study, a "median" plant generating $4.7 \times 10^{6} \mathrm{kWh} / \mathrm{yr}$ of electricity from 60,000 ton/yr of fluff would yield a before tax cash flow of about $\$ 105,000 / \mathrm{yr}$ on an investment of about $\$ 1.9$ million. A large-scale plant $(180,000$ ton/yr of fluff) would produce a cash flow of $\$ 665,000$ on an investment of $\$ 4.6$ million

A recent study conducted by the U.S. Environmental Protection Agency (EPA 1987) concluded, "The highest PCDD [polychlorinated di-benzo-P-dioxins] emissions concentrations appear to be associated with low temperature combustion processes whose function is to recover energy or other resources (e.g., metal values) by combustion of waste materials." This study also reported that the highest PCDD emissions were measured at sites containing plastics in the feed, and that total organic halogens (TOX) showed stronger association with PCDD emissions than with total chloride content. Thus, any incineration system will likely require a high-temperature afterburner to prevent such emissions, and this modification would, of course, increase the cost of the incinerator.

\section{A.4 Conclusions}

In the last three decades, several treatment and disposal methods for fluff have been investigated. Landfilling of fluff is still the most common practice. However, increasing transportation, tipping, and metal fixation costs are reducing the economic attractiveness of this approach.

Incineration is an available technology that might be cost-effective, depending on the specifics of operation (including the chemistry of the material to be treated). However, fixing of the metals content and/or postprocessing of the ash for metals recovery might be required. The technology for recovering the heat from the combustion gases for the production of steam and/or electricity is also available.

Secondary recycling to make lower-grade products is technically feasible. The main drawbacks are that there is a very limited market and that secondary products are generally not cost-competitive with products produced from virgin materials.

Although technically feasible, tertiary recycling has only been examined as an option to a limited extent. Nonetheless, we would expect some tertiary processes not to be cost-effective under current market conditions. For example, gasification of coal is a developed technology, yet the resultant cost of the product gas cannot compete with the current cost of natural gas. Because of its relative capital intensity, we do not believe that gasification economics would be significantly improved using fluff without a fee for accepting the fluff. We would expect similar economics for pyrolysis and hydrogenation, although pyrolysis might be less costly than either gasification or hydrogenation. 
One of the problems associated with attempting to recycle fluff is the variability in its composition (i.e., plastics contents, nonplastics combustibles, and inert compounds). For any of the processing alternatives that might be investigated for recycling fluff, mechanical separation of the various fractions of fluff could concentrate those compounds targeted for the recycling options in a single fraction, which would minimize the cost of attempting to use the complete fluff in the recycling process. For example, secondary recycling economics would likely be improved by concentrating the thermoplastics in a fraction, and the economics of recovering plastics using solvents would improve if the plastics were concentrated prior to solvent extraction.

Ultimately, the most cost-effective approach for recycling fluff may be a hybrid system that first incorporates physical separation to concentrate components into two or more fractions and then uses the recycling technology that can best be operated on the individual fractions.

\section{A.5 References}

Adams, R.L., 1972, An Economic Analysis of the Junk Automobile Problem, Ph.D. dissertation, University of Illinois, Champaign, Ill.

Banks, M.E., W.D. Lusk, and R.S. Ottinger, 1971, New Chemical Concepts for Utilization of Waste Plastics, U.S. Environmental Protection Agency Report SW-1GC.

Bilbrey, J.H., Jr., J.H. Sterner, and E.G. Valdez, 1979, Resource Recovery from Automobile Shredder Residue, Conservation and Recycling J., 2:219-232.

Bilbrey, J.H., K.C. Dean, J.W. Sterner, 1974, Design and Operation of an Automobile and Railroad Car Incinerator, Metal Society American Institute of Mechanical Engineers Reprint A, pp. 74-88.

Boeger, K.E., and N.R. Braton, 1990, Mill Fuel and Mill Cover Recycled from Shredder Fluff, in Center for Metals Production, CMP Report No. 90-1, Carnegie Mellon Research Institute, Pittsburgh, Jan.

Braslaw, J. and J. L. Gerlock, 1984, Polyurethane Waste Recycling 2, Polyol Recovery and Purification, Industrial and Engineering Chemistry 23:552-556.

Curlee, T.R., 1986, The Economic Feasibility of Recycling: A Case Study of Plastic Wastes, Praeger Publishing, New York.

Daellenbach, C.B., W.M. Mahan, and J. Drost, 1974, Utilization of Automobile and Ferrous Refuse Scrap in Cupola Iron Production, Proc. Fourth Mineral Waste Utilization Symp., Chicago, Ill., pp. 417-423, May 7-8.

Dean, K.C., C.J. Chindgren, E.G. Valdez, 1972, Innovations in Recycling Automotive Scrap, Annual Meeting, Institute of Scrap Iron and Steel, Inc., Washington, D.C., Jan. 15-18. 
Dean, K.C., et al., 1985, Bureau of Mines Research on Recycling Scrapped Automobiles, U.S. Department of Interior Bulletin 684.

Dean, K.C., J.W. Sterner, and E.G. Valdez, 1974, Effect of Increasing Plastics Content on Recycling of Automobiles, U.S. Bureau of Mines, Technical Progress Report TPR 79, Washington, D.C., U.S. Government Printing Office.

Dean, K.C., and J.W. Sterner, 1969, Dismantling a Typical Junk Automobile to Produce Quality Scrap, U.S. Bureau of Mines, Report of Investigations 7350, Washington, D.C., U.S. Government Printing Office.

DOE/ECUT and PIA, 1984, Program on Recycling Auto Scrap, U.S. Department of Energy/Energy Conversion and Utilization Technologies (DOE/ECUT) and the Plastics Institute of America (PIA), Inside R\&D, Vol. 13, No. 2, Jan. 11.

DuBois, J.H., and F.W. John, 1967, Plastics, 5th Ed., Van Nostrand Reinhold Company, New York.

Ellsworth, R.D., E.P. Ballinger, and R.B. Engdahl, 1957, Preliminary Survey of Development of An Incinerator for Removal of Combustibles from Scrapped Automobile Bodies, Final Report Prepared for Institute of Scrap Iron and Steel, Battelle Memorial Institute, Aug.

EPA, 1987, National Dioxin Study Tier 4-Combustion Sources, Engineering Analysis Report EPA-450/4-84-014h, prepared by Radian Corp. for the U.S. Environmental Protection Agency, Sept.

Hershey, R.L., M.D. Waugh, and E.J. Hanny, 1987, Waste Tire Utilization, Final Report by Science Management Corp., Washington, D.C., pre t ared for the U.S. Department of Energy under contract no. AC01-84CE40714, April.

Huang, C.J., and C. Dalton, 1975, Energy Recovery from Solid Waste, National Aeronautics and Space Administration Report NASA-CR-2526.

Hubble, W.S., I.G. Most, and M.R. Wolman, 1987, Investigation of the Energy Value of Automobile Shredder Residue, U.S. Department of Energy Report DOE/ID-12551.

Jody, B.J., et al., 1990, Recycling of Plastics in Automobile Shredder Residue, Proc. 25th Intersociety Energy Conversion Engineering Conf., Reno, Nev., pp. 131-135, Aug.

Kaiser, E.R., and J. Tolciss, 1961, Smokeless Burning of Automobile Bodies, New York University, College of Engineering, Technical Report 764.2.

Leidner, J., 1981, Plastics Waste; Recovery of Economic Value, Marcel Dekker, Inc., New York.

Luntz, R.A., 1973, Separation of Non-Ferrous Metals from Hammermill Fragmentizer, Scrap Age 30(10):13, Oct. 
Lynch, J.C., and E.B. Nauman, 1989, Separation of Commingled Plastics by Selective Dissolution, Proc. Society of Plastics Engineers Regional Technical Conference, Charlotte, N.C., Oct. 30.

Mack, W., 1971, Recycling Plastics at a Profit, Proc. 28th Annual Western Conf. of Society Plastics Industry, May.

Mahoney, L.R., S.A. Weiner, and F.C. Farris, 1974, Hydrolysis of Polyurethane Foam Waste, Environmental Science and Technology, 8(2):135-139.

MSREF, 1983, Shredder Residue, Metal Scrap Research and Educational Foundation (MSREF), Washington, D.C., Dec.

Plastics Institute of America, 1980, Maximizing the Life Cycle of Plastics, Final Report, available from the Plastics Institute of America, Inc., at Stevens Institute of Technology, Castle Point, Hoboken, N.J., Feb.

Plastics Institute of America, 1987a, Secondary Reclamation of Plastics Waste, Phase 1 ReportDevelopment of Techniques for Preparation and Formulation: Automobile/Appliances Shredder Residue, Mixed Industrial Waste, Curbside Separated Consumer Waste, available from the Plastics Institute of America, Inc., at Stevens Institute of Technology, Castle Point, Hoboken, N.J.

Plastics Institute of America, 1987b, Secondary Reclamation of Plastics Waste, Phase 2 Report Evaluation of Industrial Processes: Financial Analysis and Potential Markets, available from the Plastics Institute of America, Inc., at Stevens Institute of Technology, Castle Point, Hoboken, N.J.

Sawyer, W., 1974, Automotive Scrap Recycling: Processes, Prices, and Prospects, Resources for the Future, Inc., Baltimore, Md.

Schmitt, R.J., 1990, Automobile Shredder Residue: The Problem and Potential Solutions, in Center for Metals Production, CMP Report No. 90-1, Carnegie Mellon Research Institute, Pittsburgh, Jan.

Scrap Age, 1974, Auto Shredder Reduces Junk Cars in Michigan, Scrap Age, 31(12):104, 107, and 108, Dec.

Sterner, J.W., D.K. Steele, and M.B. Shirts, 1984, Hand Dismantling and Shredding of Japanese Automobiles to Determine Material Contents and Metal Recoveries, U.S. Bureau of Mines, Report of Investigations 8855, Washington, D.C., U.S. Government Printing Office.

Tesoro, G., 1987, Recycling of Synthetic Polymers for Energy Conservation - The State of the Art, Polymer News, 12:265-268. 
Valdez, E.G., K.C. Dean, and J.H. Bilbrey, 1975, Recovering Polyurethane Foam and Other Plastics from Auto Shredder Reject, U.S. Bureau of Mines, Report of Investigations 8091, Washington, D.C., U.S. Government Printing Office.

Warner, A.J., C.H. Parker, and B. Baum, 1970, Solid Waste Management of Plastics, Report for the Manufacturing Chemists Association, prepared by DeBell and Richardson, Inc., Washington, D.C.

Woodruff, K.L., B.D. Mechel, and D.M. Albertson, 1990, Development of a Fluidized Bed Combustion System for Auto Shredder Residue, in Center for Metals Production, CMP Report No. 90-1, Carnegie Mellon Research Institute, Pittsburgh, Jan. 


\section{DISTRIBUTION FOR ANL/ESD-13}

\section{Internal}

ANL Contract Copy

K.S. Macal (7)

ANL Patent Department

B. Jody (100)

ANL Technical Publications Services (3)

\section{External}

U.S. Department of Energy Office of Scientific and Technical Information (12)

Manager, U.S. Department of Energy Chicago Operations Office

ANL Libraries 

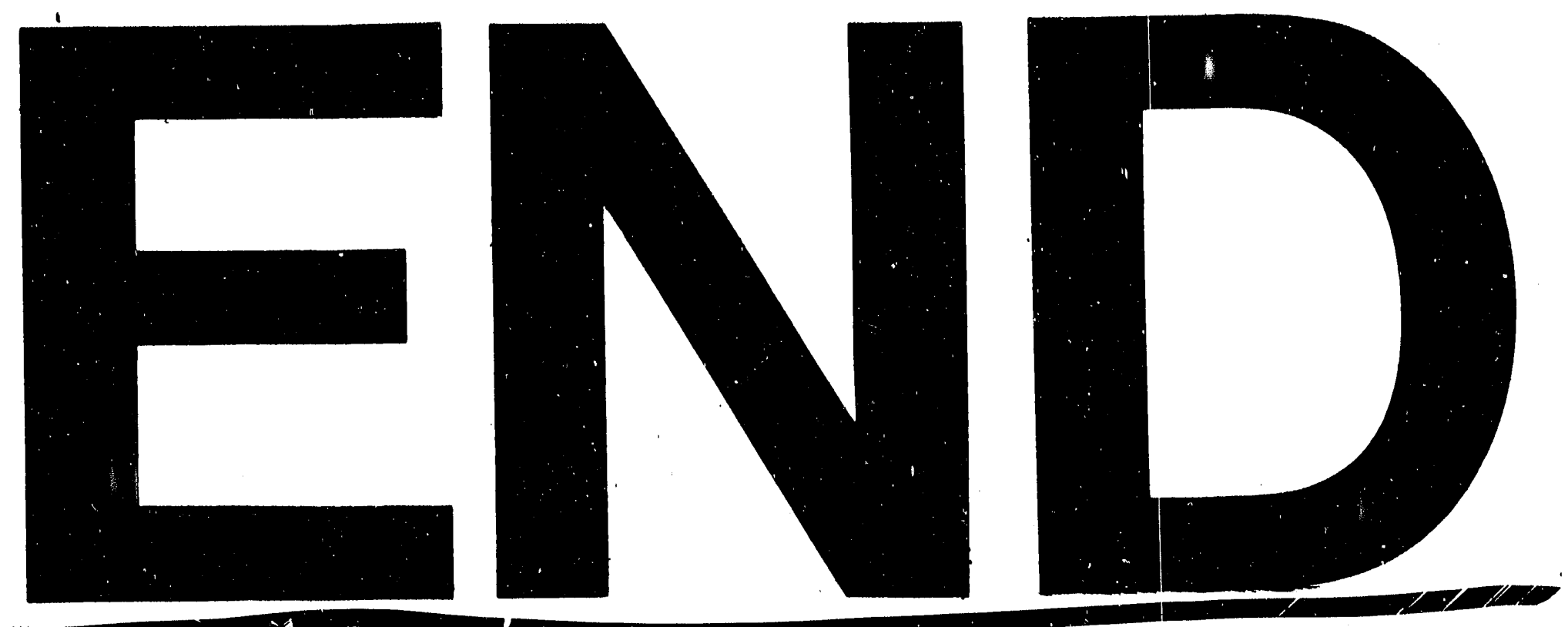

sive
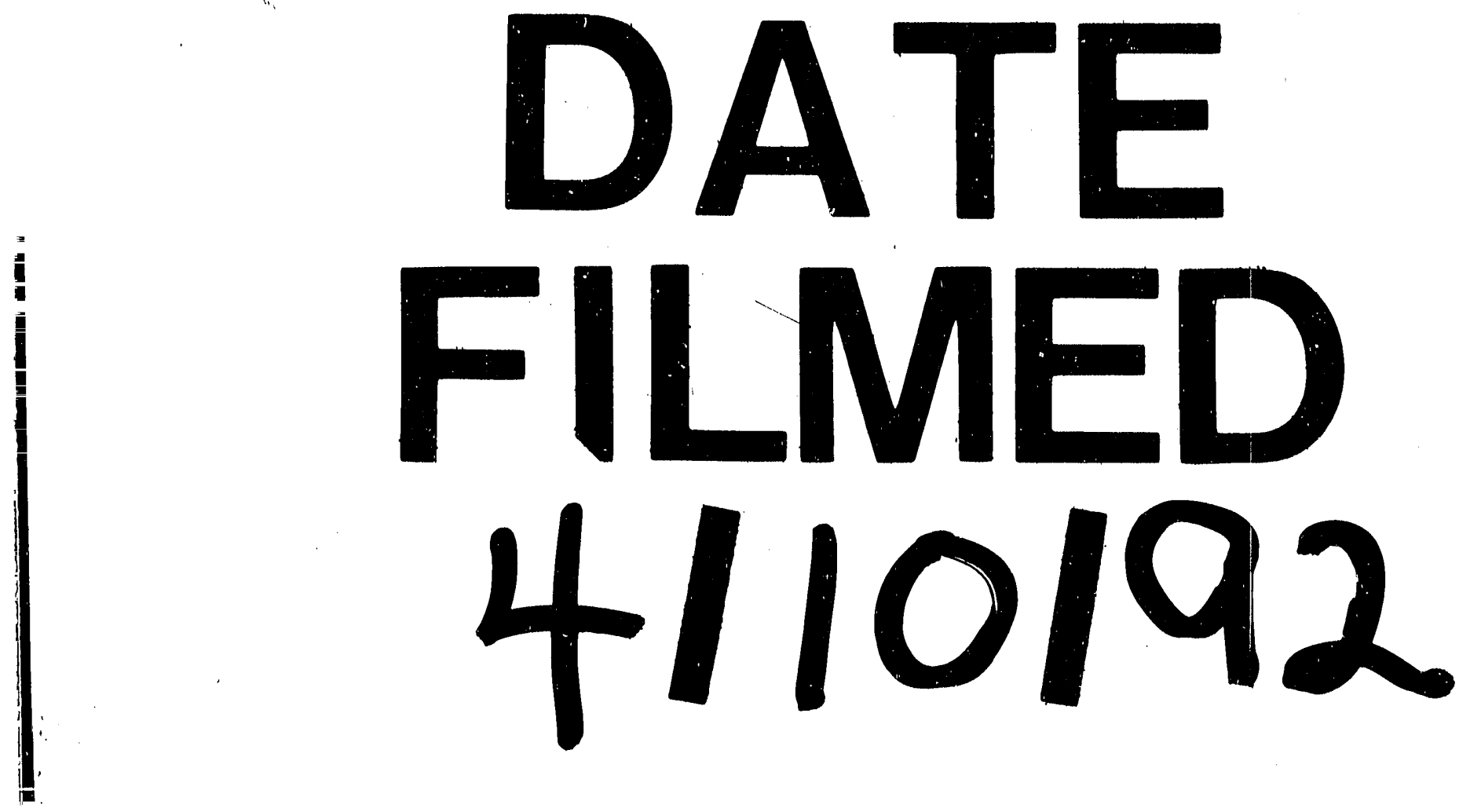


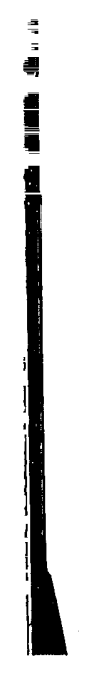

